Florida International University

FIU Digital Commons

FIU Electronic Theses and Dissertations

University Graduate School

3-8-1994

\title{
A descriptive study of university students' beliefs regarding autonomy and paternalism in caregiving of the elderly
}

Linda Ann Cain

Florida International University

DOI: $10.25148 /$ etd.FI14052532

Follow this and additional works at: https://digitalcommons.fiu.edu/etd

Part of the Occupational Therapy Commons

\section{Recommended Citation}

Cain, Linda Ann, "A descriptive study of university students' beliefs regarding autonomy and paternalism in caregiving of the elderly" (1994). FIU Electronic Theses and Dissertations. 1968.

https://digitalcommons.fiu.edu/etd/1968

This work is brought to you for free and open access by the University Graduate School at FIU Digital Commons. It has been accepted for inclusion in FIU Electronic Theses and Dissertations by an authorized administrator of FIU Digital Commons. For more information, please contact dcc@fiu.edu. 
FLORIDA INTERNATIONAL UNIVERSITY

Miami, Florida

A DESCRIPTIVE STUDY OF UNIVERSITY STUDENTS'

BELIEFS REGARDING AUTONOMY AND PATERNALISM IN

CAREGIVING OF THE ELDERLY

A thesis submitted in partial satisfaction of the requirements for the degree of

MASTER OF SCIENCE

in

OCCUPATIONAL THERAPY

by

Linda Ann Cain

1994 
To: Dean William J. Keppler

College of Health

This thesis, written by Linda Ann Cain, and entitled A Descriptive Study of University Students' Beliefs Regarding Autonomy and Paternalism in Caregiving of the Elderly, having been approved in respect to style and intellectual content, is referred to you for judgement.

We have read this thesis and recommend that it be approved.

Susan Kaplan, PhD, OTR/L

Paulette Johnson, PhD

Gail Hills Maguire, PhD, OTR/L Major Professor

Date of Defense: March 8, 1994

The thesis of Linda Ann Cain is approved.

Dean William J. Keppler

Collqgie of Health

Dr. Richard L. Campbell

Dean of Graduate Studies

Florida International University, 1994 
I dedicate this thesis to my parents. Without their patience, understanding, support, and most of all love, the completion of this work would not have been possible. 
ACKNOWLEDGEMENTS

I wish to express my sincere appreciation to those who contributed to the completion of my thesis. To the members of my thesis committee, Dr. Susan Kaplan and Dr. Paulette Johnson, and my chairperson, Dr. Gail Hills Maguire, I greatly appreciate the guidance, expert knowledge and encouragement, I needed in order to complete my thesis and the extra time and energy required when this project became long distance. In addition, I am grateful to Dr. Maguire for allowing me to participate in her research project. I consider it an honor to be the first person to present a thesis from this on-going study.

I would also like to express my gratitude to the following extraordinary individuals: To Joanne Gallagher, for the encouragement, expert advise, and her proficient navigational skills to transport my documents from place to place. To Martha Belote, my OT colleague and good friend, who together we motivated each other to finally accomplish our goals side by side, CONGRATULATIONS! To my friends, especially Argus Galindo, Walter Bridgham and my co-workers at RehabWorks, who provided continual support and encouragement throughout this project. To Sharon Orend and Dee Foster, for their invaluable assistance in the last legs of my thesis. To my family, especially my parents, for their enduring patience, support and unconditional love, to whom this thesis is dedicated. 


\section{ABSTRACT OF THE THESIS \\ DESCRIPTIVE STUDY OF UNIVERSITY STUDENTS' BELIEFS REGARDING \\ AUTONOMY AND PATERNALISM IN CAREGIVING OF THE ELDERLY \\ by}

Linda Ann Cain

Florida International University, 1994

Miami, Florida

\section{Professor Gail Hills Maguire, Major Professor}

An elderly person with declining physical and mental abilities associated with aging or disease, often needs assistance from others for functional activities. The beliefs in autonomy and paternalism of those who render assistance to the elderly may influence their behavior toward the elderly. The purpose of this study was to identify university students' beliefs regarding autonomy and paternalism in caregiving of the elderly and to determine if there were any differences in beliefs between educational levels. Seventy-two undergraduate and graduate occupational therapy students (mean age 28.3) volunteered to participate in this study. The measurement instruments included: the Respect for Autonomy Scale (Cicirelli, 1989) and Paternalism Scale (Cicirelli, 1989) and a demographic survey. Overall, students agreed more with autonomous statements and remained neutral with paternalistic 
statements. The $\underline{t}$-tests showed a significant difference in beliefs between educational levels. The graduate students disagreed more with paternalistic statements than undergraduate students. 
LIST OF TABLES $\ldots \ldots \ldots \ldots \ldots \ldots \ldots \ldots \ldots \ldots \ldots \ldots \ldots \ldots \ldots \ldots \ldots$

CHAPTER PAGE

I. INTRODUCTION $\ldots \ldots \ldots \ldots \ldots \ldots \ldots \ldots \ldots \ldots \ldots \ldots \ldots \ldots \ldots \ldots$

II. Literature REVIEW ................... 7

Elderly in the United States ............. 7

Attitudes Toward the Elderly ............. 8

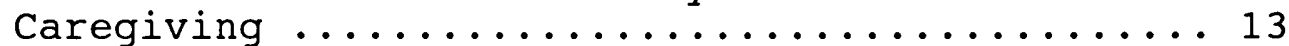

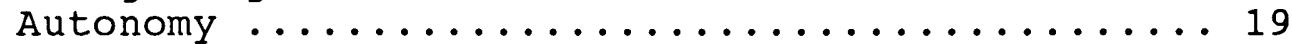

Theoretical Approach to Elderly and Autonomy ... 32

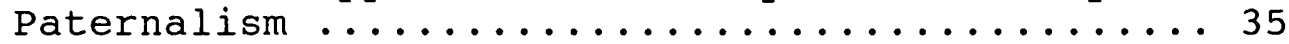

Respect for Autonomy and Paternalism Scales .... 44

III. RESEARCH PROCEDURE/METHODOLOGY ......... 51

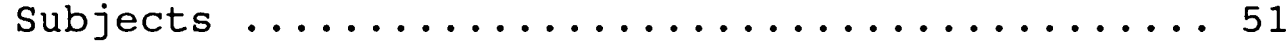

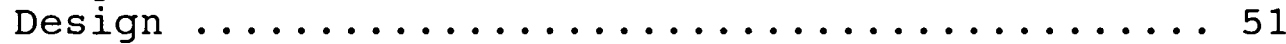

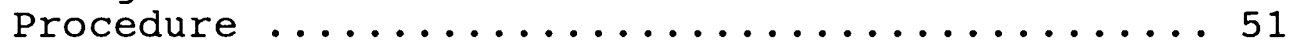

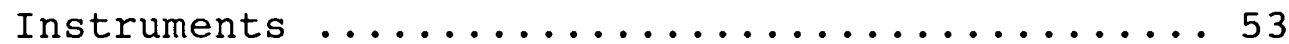

Statistical Analysis ................ 54

Limitations of the study .............. 55

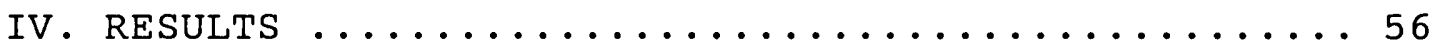

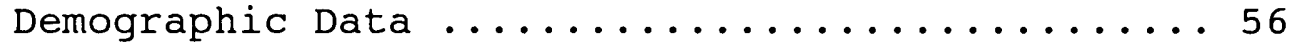

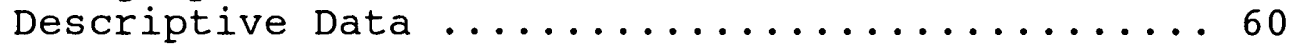

Statistical Analysis ..................67

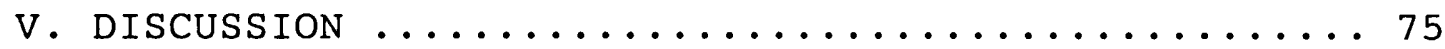

Research Questions ................. 75

Comparison of the Current study

to Cicirelli's study ................ 80

Relationships Between Autonomy

and Paternalism ........................ 81

Variables that Affect Autonomous

and Paternalistic Beliefs ............. 82

Application of Theory to Elderly Autonomy ..... 84

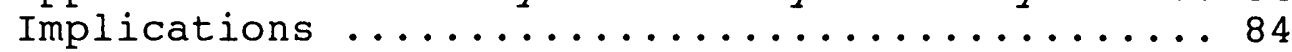

Recommendations .................. 86

Summary $\ldots \ldots \ldots \ldots \ldots \ldots \ldots \ldots \ldots \ldots$

LIST OF REFERENCES $\ldots \ldots \ldots \ldots \ldots \ldots \ldots \ldots \ldots \ldots$

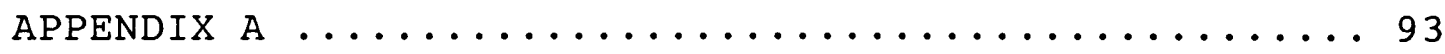


1. Internal Consistency Reliability

for Autonomy and Paternalism Scales ........ 59

2. Autonomy Scores, Factors, and

Subtypes by Educational Level ..........661

3. Paternalism Scores and

Subtypes by Educational Level $\ldots \ldots \ldots \ldots \ldots \ldots 2$

4. Overall Students' Scores

on the Respect for Autonomy scale .........66 63

5. Overall Students' Scores

on the Paternalism Scale ............. 64

6. Comparison of Means and

Standard Deviations of Two Studies $\ldots \ldots \ldots \ldots 6$

7. Correlation of Autonomy

with Paternalism .................... 71

8. Correlation of Age with the

Autonomy and Paternalism Scales ..........73 


\section{Introduction}

Elderly in the United States

In 1990, it was estimated that $12.6 \%$ ( 31 million) of the United States population consisted of individuals 65 and older (U.S. Census Bureau, 1991). By the year 2010, it is estimated that this percentage will increase to 148 or to 39 million. Due to the advancements in the medical field and preventive health care, a great number of individuals are living pass the age of 65, as compared to a century ago. The number of people in 1900 who were 80 years or older was 374,000 as compared to $7,000,000$ in 1990. This provides the older population with the rewards and the challenges of living a longer life. It is also a challenge to the health care system to provide services to an elderly population, who can become more dependent with age.

As people grow older, they are faced with the changes associated with aging. With a decline in physical and mental abilities, it can become more difficult to manage and perform one's personal activities, i.e., health, finances, transportation, self-care, and home management. Furthermore, with an increased dependence on others to assist in daily tasks, it can become more difficult to maintain one's autonomy •

In 1986 , it was estimated that $6.7 \%$ of males and 12.18 of females reported needing assistance from others in one or more areas of personal activities (National Center for Health 
Statistics, 1992). Age was a major factor in determining the amount of assistance needed. As evidenced by the report, 5.9\% of people ages 65 to $74 ; 13.5 \%$ of people ages 75 to $84 ;$ and more dramatically $28.8 \%$ of people 85 and older required assistance in one or more areas of personal activities (National Center for Health Statistics, 1992).

One challenge for the elderly is ensuring the respect for their autonomy by others, especially by those providing assistance to them. As early as 1959, Kant defined autonomy as the right of every individual to make choices and act upon those choices, providing those choices are not harmful to others (Cicirelli, 1989). Sometimes families, friends or health care professionals providing assistance to the elderly unneccesarily act paternalistically and make decisions for elderly individuals without their consent, thus minimizing the elderly individuals' autonomy (Cicirelli, 1990). Paternalistic choices made by caregivers have an impact on individuals' self-esteem and self-worth (Abramson, 1985).

Individual gain positive life experiences when they believe in their essential freedom and the ability to control their lives (Kielhofner, 1985). Erikson also stated that profound life satisfaction is achieved by autonomous individuals who are able to value themselves through their own successes and failures (Bruce \& Borg, 1987). It has been empirically shown that a person's right to exercise autonomy has positive effects on life satisfaction and an individual's 
well-being (Langer \& Rodin, 1976; Reid \& Zeigler, 1980; Schulz, 1976).

The model of human occupation (Kielhofner, 1985) describes occupational behavior as composed of a hierarchy of three subsystems. These three subsystems: volition, habituation, and performance, work together to allow individuals to explore and master their environment. Functional individuals are those who have been able to maintain self-determination; to be productive members of society; and to participate in daily activities such as selfcare and recreation/leisure throughout their lifespan.

As people grow older, they usually experience difficulties in all three subsystems. Problems, such as sensory loss, disuse or misuse atrophy and chronic diseases affect an individual's ability to perform daily tasks (performance subsystem). The decrease in the ability to perform daily tasks causes a loss of roles and habits (habituation subsystem). Problems are created when trying to balance new routines and roles with previous habits.

Furthermore, due to changes in roles and performance skills, individuals can feel a lack of efficacy and control of their lives (volition subsystem). Kielhofner (1985) states that elderly individuals can maintain or gain feelings of efficacy and control of planning their life decisions through continual practice and skill building. It is also suggested that caregivers of the elderly can use a balance of support 
and respect for the autonomy of the elderly to promote a sense of control in elderly individuals' lives.

\section{Statement of the Problem}

Every individual has the right to make decisions and act upon those decisions. This ability to be autonomous in one's life is related to life satisfaction and a sense of wellbeing. If this right of self-determination is not exercised, a person experiences disharmony.

An elderly person, with declining physical abilities, often needs assistance from others for functional activities. Sometimes those who render assistance to the elderly inappropriately make paternalistic decisions on the behalf of an elderly individual, thus minimizing their right of autonomy. Conflicts can arise when elderly individuals object to a loss of control in their lives, which can result in caregivers perceiving the elderly individual as uncooperative.

The focus in occupational therapy is to maximize individuals' autonomy and independence through functional and personally relevant activities. It is important not only to rehabilitate elderly individuals to their maximum functional level, but facilitate autonomy of the elderly when working with elderly individuals and their caregivers. Information regarding the beliefs of occupational therapy students toward autonomy and paternalism in caregiving of the elderly gives an indication of how they may support autonomy when working with the elderly as health care providers. 
Research Questions

What are the beliefs of occupational therapy students regarding autonomy and paternalism in caregiving of the elderly?

Are there any differences in the beliefs regarding respect for autonomy and paternalism in caregiving of the elderly between undergraduate and graduate occupational therapy students?

\section{Definitions}

(1) autonomy- the condition or quality of being selfgoverning (The Shorter Oxford English Dictionary, 1993)

(2) paternalism- a policy or practice of treating or governing people, especially providing for their needs without giving them responsibility (The shorter Oxford English Dictionary, 1993)

(3) caregiving- the act of providing assistance to an individual in need (Cicirelli, 1989)

(4) caregiver- a person providing some degree of care in response to an older person's needs (Horowitz and Dobrof, 1982; Cicirelli, 1990)

(5) elderly- a person over the age of 65 (U.S. Census Bureau, 1991)

(6) belief- a subjective judgement that objects (or ideas) exist, tends to be durable and influence behavior (Cicirelli, 1989)

(7) attitudes- a state of mind or feeling with regard to 
some matter; disposition (The Shorter Oxford English Dictionary, 1993)

(8) Respect for Autonomy Scale and Paternalism Scaledeveloped by Vincent Cicirelli in 1989, to measure beliefs of caregivers in regard to elderly caregiving (Cicirelli, 1989)

\section{Significance of the Study}

The significance of the study was to describe university students' beliefs with respect to autonomy and paternalism regarding caregiving of the elderly.

It is assumed that these beliefs affect how individuals interact and care for the elderly. It is expected that occupational therapy students who indicate supportive autonomy attitudes in caregiving of the elderly will be more apt to support autonomy when working with the elderly.

\section{Assumptions}

The following assumptions were made:

1) The concept of autonomy or individuals' ability to make their own decisions exist in society.

2) The university students surveyed have had contact with or knowledge of elderly individuals.

3) Participants answered the questionnaires honestly, thus reflecting their beliefs in autonomy and paternalism in the elderly. 


\section{Literature Review}

Elderly in the United States

In 1990, there were 31 million people in the United States who were 65 years or older, accounting for 12.68 of the total population. Seven million elderly were 80 years or older (U.S. Census Bureau, 1991). Since 1980, the older population ( 65 and older) has increased $22 \%$ from 25 million and is projected to increase to 39 million or $14 \%$ of the total population by the year 2010 (U.S. Census Bureau, 1991). After 2010, the elderly population will substantially increase as the Baby Boom generation (born 1946 to 1964) matures (U.S. Census Bureau, 1991). Due to the continued growth of the elderly population, responsibility is placed on American families, the government, and the health care system to meet the needs of this population.

The elderly have a variety of needs depending on their abilities and disabilities. Decisions on where to live and who will care for the elderly depend upon their health, social supports, mental status, and financial situation. In 1990, $56 \%$ of the older population lived alone or with their spouse in their own homes or apartments. Five percent or 1.6 million elderly lived in institutions (U.S. Census Bureau, 1991).

In 1986 , it was reported that $6.7 \%$ of males and $12.1 \%$ of females aged 65 and over, needed assistance with one or more activities of daily living, i.e., self care, mobility, home management and transportation. The majority of the people 
requiring assistance were 85 years or older (National Center for Health Statistics 1992).

\section{Attitudes Toward the Elderly}

A meta-analysis of the literature. Many gerontological research studies have focused on the identification of attitudes toward the aging process and the elderly. Kite (1988) conducted a meta-analysis of the literature from the years 1960 to 1985. The sample consisted of 43 articles examining people's attitudes toward the elderly and attitudes toward young people. Kite reported that the majority of the articles showed that people held more negative attitudes toward elderly than toward young people. A few articles in Kite's literature review showed either no differences in attitudes or positive attitudes toward the elderly (Kite, 1988 )

Difficulty with attitude evaluation tools. Kite (1988) stated a number of factors have an impact as to why research studies find that people have negative attitudes toward the elderly. It was explained that "attitudes toward the elderly appear to be composed of conceptually different domains and are multivariately determined" (p. 240). People appear to hold a variety of beliefs about older people depending upon the situation.

In addition, Kite (1988) stated that evaluation tools ask people to make judgements from little information, thus forcing them to rely on societal stereotypes of the elderly on 
which to base their attitudes. Kite (1988) demonstrated this in a study by showing that attitudes can be influenced by research factors such as: type of research design; method of evaluative measurements; or the experimental setting, i.e., lab versus field study. Therefore, Kite (1988) suggested a need for researchers to control these various factors in their studies to produce valid results of people's attitudes toward the elderly.

Positive attitudes. Studies have been conducted to identify attitudes of middle aged and older adults toward the elderly (Rothbaum, 1983). In three different studies, Rothbaum (1983) examined the perceptions of older adulthood by two different age groups. Two groups consisted of males and females aged 30 to 45 years old and males and females aged 55 to 70 years old. The first and the second studies were similar, containing 20 males and 20 females from each of the two age groups, for a total of 80 in each study. Questionnaires were administered asking the subjects to rate 100 adjectives to indicate the degree to which they felt the adjective was a characteristic of the 30 to 45 year old age group versus the 55 to 70 year old age group. In both studies, similar results were found. The subjects in both age groups assigned more positive than negative characteristics to the different age groups, indicating that there was an absence of ingroup evaluative bias (Rothbaum, 1983).

The third study had different subjects than those in the first two studies. Again, subjects included 20 from each sex 
and age group, for a total of 80 subjects. A different questionnaire was administered in this study consisting of 60 adjectives in which the subjects were asked to rate each adjective on a five point scale ranging from "extremely admirable" to "extremely unadmirable." The results showed that the older adults gave more positive ratings of the adjectives than did the younger adults, indicating ingroup evaluative bias. Rothbaum (1983) explained that the results suggest that "as persons enter old age, they form an increasingly admiring view of characteristics associated with older adults" (p. 180).

Attitudes and personality traits. Studies by Katz (1990) and Kogan (1961) found that attitudes toward the elderly were clearly related to personality traits and personal characteristics. Kogan (1961) found that individuals with a nurturant personality had a more favorable attitude toward the elderly. Negative attitudes toward the elderly were correlated to traits of authoritarism and anomie. Individuals that tended to have unfavorable attitudes toward minority groups (i.e., ethnic, physical disabled and mentally ill) tended to have unfavorable attitudes toward the elderly.

In a study by Katz (1990), three personality groupings were related to positive attitudes toward the elderly: low anxiety traits, sensitive-intuitive traits and intellectual ability. Characteristics of individuals considered to fit into the low anxiety group included those who were less anxious, had high ego strength and confidence and were 
emotionally stable. Individuals considered to fit into the sensitive-intuitive group were described as tender-minded, clinging, dependent and sensitive. Individuals that were considered to be more thoughtful, cultured, and had more intellectual interests were characteristics of the intelligent group. Katz (1990) also concluded that older people, women and individuals from a higher educational background tended to have more positive attitudes toward the elderly.

University students' attitudes toward the elderly. In 1961, Kogan sampled 296 students from two northeastern universities to study their attitudes toward old people. In the same study, personality traits and attitudes were also compared. The questionnaire consisted of 17 items expressing stereotypical negative statements and 17 positive statements concerning old people. The subjects were asked to rate the statements on a five point rating scale on how much they agreed or disagreed with the statements. It was reported that the subjects disagreed more with the statements expressing negative sentiments of old people than they agreed with statements praising old people. There was no significant difference between male and female subjects. Kogan (1961) concluded that those college students tended to hold more favorable attitudes toward the elderly than unfavorable.

In 1988, Waskel and Powell asked 217 university students to write down the first four words that came to mind when the words aged or elderly were used. This exercise was then repeated by 108 students selected from the former group and 
instructed to interview a person 20 years older than they were. A list of the 40 most commonly mentioned words to describe aged or elderly was complied from the list that the students gave to serve as an instrument for a second study. In the second study, the list of 40 words was the instrument administered to 164 students and 66 older persons. The subjects were asked to rate each word on a scale of 0 to 100, beginning with 0 if the word was never applicable to the elderly to 100 if the word was most applicable to the elderly. In the first section, the subjects were to rate the words according to the elderly in general. The second section they were asked to think of one of their older relatives, a person 65 or older, when rating the same set of 40 words.

Waskel and Powell (1988) reported that the subjects did not hold negative attitudes toward the aged in a global context nor in regard to an older relative. Subjects assigned neutral ratings to negative words when the words were associated with the aged in general. When the negative words were associated to an older relative, the subjects felt the words were not applicable. Subjects rated that positive words did apply to the aged in general and were more applicable when regarding their older relative. Waskel and Powell concluded that even though subjects chose both negative and positive words to describe the aged, these words may not necessarily reflect negative attitudes toward the aged.

Schwalb and Sedlacek (1990) conducted a study in 1979 and again in 1988 to explore university students' attitudes toward 
elderly individuals over time. The samples were taken from a freshman orientation in 1979 and again in 1988; there were no repeat subjects in these studies. There was a total of 412 participants in both studies. The questionnaire was a version of the SAS-A, an instrument consisting of 10 situations relevant to college life. The subjects were to rate, on a Semantic Differential scale, a set of 10 descriptive words that followed each situation. Two different forms of the instrument were used in this study: Form $A$ was a control situation with no specific age mentioned and Form $B$ was experimental with mention of specific age. Each subject was randomly assigned one of the forms to fill out.

The results showed that students responded more negatively on Form B (age-specified) in academic and social situations than the students with Form A (age not specified). It was reported, in the majority of the situations, students held negative attitudes toward the age-specific older people, 6 out of 10 in 1979 and 7 out of 10 in 1988. Schwalb and Sedlacek (1990) concluded that students held negative attitudes toward older people over the period of time studied.

\section{Caregiving}

Historical trends affecting caregiving. Horowitz and Dobrof (1982) defined caregiver as a person providing some degree of care in response to an older person's needs. Caregiving is the act of providing this assistance. Articles by Ward (1978) and Hareven (1983) discussed the changes in 
aspects of caregiving during this century. In pre-industrial times, extended families played the most important role in providing economic and social security to older family members. At this time, public resources to assist the elderly were few and considered the "last resort" (Hareven, 1983).

The Great Depression, World War II and the industrialization of America were events that changed people's perceptions about careers and family, thus affecting families' roles in caring for the elderly (Hareven, 1983; Ward, 1978). During these times, parents encouraged their children to find good employment to bring them out of the ranks of low economic status. Younger generations in rural areas, moved away from families to urban areas in order to find work and raise their own families. They developed a life-style which involved privacy, autonomy, and self-sufficiency (Hareven, 1983). With this more autonomous life-style, the willingness of adult children to sacrifice their own lives to help the aged decreased (Ward, 1978).

The older members of this changing society also responded to the industrialization of the nation. Programs such as Social Security, savings, and pension plans enabled many older people to support themselves financially and live as they wished (Brody, 1985). With the start of the Social security Program in 1935, the number of elderly parents depending solely on their children for financial support dropped from 508 in 1937 to 1.58 in 1979 (Brody, 1985). More elderly people began living independently from their extended 
families. They also became less willing to request assistance from their adult children for fear of becoming dependent or burdensome (Ward, 1978).

Current trends affecting caregiving. In 1986, Doty stated that informal family caregiving has remained at a high level. Research shows that a majority of elderly parents live in close proximity and have regular interaction with their adult children (Ward, 1978). There is little evidence to support the popular notion that there has been a decrease in family caregiving. Doty (1986) reported that many impaired elderly living in the community were as functionally and medically involved as nursing home residents, but they were able to remain in the community because of family assistance. Many researchers reported that changes in society limit the amount of caregiving the family provides to their elderly members (Treas, 1977; Brody, Poulshock \& Masciocchi, 1978; Ward, 1978; Cicirelli, 1983). One of those changes is women working outside their homes. Not only did this trend affect elderly caregiving, but also increased the pressures on women and their families (Brody, 1985). Brody (1985) stated that women were still committed to care of their elderly parents, but used public resources, such as hired help, rather than leaving the work force.

Advanced medical technology is another change in society which affects caregiving. Today, people are living longer after the onset of disease or disability, as compared to earlier in this century. This places more stress on families 
and the health care system to care for those that live to a very old age (Brody, 1985). Furthermore, adult children of very old parents are elderly themselves and may have their own needs for assistance.

Factors that affect caregiving. There are social and psychological factors that affect the amount or type of care adult children give to their elderly parents. In 1977, Sussman reported that assistance to elderly parents varied in extensiveness and time depending on mutual aid and socialization patterns already in existence prior to an illness or crisis. This was also supported in a study by Cicirelli (1983) and documented in articles by Brody (1985) and Horowitz and Dobrof (1982).

Cicirelli (1983) identified social and psychological factors that determined the amount of help adult children gave to their elderly parents. In the study, Cicirelli surveyed 148 adult children with living elderly mothers over the age of 60. The survey assessed attachment behaviors (i.e., proximity to the parent, frequency of visiting and telephoning), filial obligation, interpersonal conflict between the adult child and the parent, mother's dependency, negative feelings of assisting the elderly parent, amount of help presently provided to the parent (helping behavior) and the commitment to provide future help.

The results showed that helping behavior or caregiving was a direct function of attachment behaviors (proximity and frequency of calling and visiting) and the mother's 
dependency. Increased attachment behavior and greater dependency resulted in greater helping behavior. Interpersonal conflict with the mother had no effect on helping behaviors, while filial obligation and feelings of attachment had an indirect effect on helping behaviors. A greater commitment to future help was dependent upon the amount of present helping behaviors, attachment behaviors, feelings of attachment, interpersonal conflict and mother dependency.

Some other factors have been identified to affect the extent of caregiving. Horowitz and Dobrof (1982) stated that persons with lower income, never married, or who were not employed tended to give more assistance to their elderly parents. In a study by Cicirelli (1983), it was reported that divorced adult children gave less help than adult children with intact marriages. Many researchers stated that women provide more care to elderly parents than men (Ward, 1978; Hareven, 1983; Cicirelli, 1983; Brody, 1985).

The rewards and the stresses of caregiving. An article by Doty (1986) suggested that family caregiving is motivated by three factors: love and affection toward the elderly parent, a sense of gratitude and desire to reciprocate caregiving and filial responsibility. A study by Horowitz and Dobrof (1982) reported similar results citing familial responsibility was the most common reason for providing assistance to elderly parents. Love was the second most common, followed by reciprocity. Adult children may get a 
sense of accomplishment and pride by being able to help their loved ones in their time of need (Horowitz and Dobrof, 1982). Families providing care to elderly members experience psychological, social and emotional strains from being in caregiving roles. Doty (1986) described the stress placed on women in caregiving roles. Limited time must be divided between their husbands, children, and career demands. Tensions may result from their husbands and children feeling neglected and the women being pulled in too many directions. Brody (1985) explained that families assuming caregiving of their elderly parents are affected by interference with their life-style, privacy, socialization, vacations, future plans, and income. In the long run, these stress factors may bring about mental health symptoms, such as, depression, anxiety, frustration, and a decline in physical health of family members (Brody 1985).

One published study exemplifies the stresses of caring for the elderly. Arling and McAuley (1983) surveyed family members of persons applying for nursing home placements. Seventy-four family members were asked to discuss the changes in their lives during the last six months prior to seeking institutional placement for their elderly relative. Fortythree percent of the surveyed family members reported that they had to plan all activities around caregiving duties. Thirty-one percent reported a decrease in social or recreational activities. Forty-two percent said they had less time for themselves, and $28 \%$ had less time with their spouse 
or children. Forty-one percent reported mental anguish or worry due to caregiving responsibilities. Eleven percent reported that social/emotional stresses outweighed financial strains or interference with careers.

\section{Autonomy}

Definition of autonomy. The Constitution of the United States emphasizes and defends an individual's right for autonomy, independence and personal freedom (Clark, 1991). The New Shorter Oxford English Dictionary (1993) defines autonomy as the right or condition of being self-governing; freedom from external control or influence. It is synonymous with the words self-determination and independence. As early as 1959, Kant described the concept of autonomy as an individual's right to identify and evaluate choices, to make and implement those choices provided they are not harmful to others (Cicirelli, 1989). Thomasma (1984) described five freedoms associated with autonomy, 1) freedom from obstacles to carry out one's desire, 2) freedom to know one's options, 3) freedom to choose or make a decision, 4) freedom to act on that decision, and 5) freedom to create new options.

Regardless of age, sex, race, ethnic background, religious affiliation or physical/mental condition, all individuals have the right to be autonomous. A belief in autonomy is one's acceptance that other people have the right to make choices and act upon those choices without intrusion by any individual (Cicirelli, 1989). In 1988, an article was 
published by Cohen discussing the constraints on autonomy for elderly individuals with disabilities. In the article, Cohen equated society's discrimination of the disabled elderly (or lack of respect for autonomy) to the discrimination of retarded citizens, the physically disabled and women. The three latter groups have campaigned for society to identify and respect their right to be autonomous individuals. Cohen stated that the disabled elderly should have their rights protected just as these other groups have in the past. It was suggested that the elderly should receive this protection through political action, as well as the reformation of community-based programs to promote independence and growth instead of encouragement of dependency and acceptance of limitations.

Cicirelli (1989) summarized five categories of autonomy. These categories were introduced by Collopy (1986), Gillon (1985) and Young (1986) to illustrate that autonomy may exist on many different levels. The categories are described below:

1) Direct autonomy- an elderly individual makes decisions alone.

2) Consultant autonomy- an elderly individual makes decisions after consulting with another individual.

3) Joint autonomy- an elderly individual and another individual make decisions together.

4 ) Delegated autonomy- an elderly individual freely delegates another individual to make decisions, either as the elderly individual would want or what the delegated 
individual feels that is best for the elderly person.

5) Surrogate autonomy- another individual voluntarily assumes decision making power in the event that the elderly individual is incapacitated. This decision is to made on the basis of what the elderly individual would choose (Cicirelli, 1989).

Importance of autonomy. Studies have been conducted with the elderly population to identify the importance of autonomy to an individual's well-being. In 1976, Schulz conducted a study on 42 elderly individuals living in a retirement home on the effects of control and predictability on their physical and psychological well-being. The subjects were interviewed and given questionnaires to determine their levels of daily activity, hope, and perceptions of their future. The subjects were divided into four groups, three experimental and one control. The three experimental groups were visited by undergraduate students and the fourth group was not. Subjects in the first group were able to control both the duration and the frequency of the visit by an undergraduate student. The second group was informed when to expect the student visitor and how long the student would stay. The third group was not notified when they would receive the visitor. The control group did not receive any visitors.

From this study, Schulz (1976) was able to show positive benefits in the areas of health, psychological status and activity level from the first and the second groups as compared to the third and fourth groups. In the area of 
health, the first and second group were rated as significantly healthier by the activities director and the request for medications decreased as compared to the third and fourth groups. In the area of psychological status, the first and second groups perceived themselves as significantly happier and having more zest for life than the third and fourth groups. In the area of activity level, the first and second groups exhibited a more positive change in daily activities and time devoted to future commitments. In conclusion, the factors of perceived control and predictability were shown to increase the well-being of the subjects.

Langer and Rodin (1976) also examined the effects of autonomy and self-determination on an elderly person's wellbeing. Ninety-one subjects who lived on two different floors in a nursing home were administered questionnaires and evaluated one week prior to the beginning of the experiment. The questionnaires assessed the subjects' current level of happiness, activity level and perceived control by selfreport. An interviewer rated the subjects' level of alertness and the nursing staff rated general improvement, time spent visiting with patients, staff, and others.

At the beginning of the experimental treatment, the nursing home administrator called a meeting in the lounge of each floor. He communicated to the residents two different messages. One group, the responsibility-induced group, received a communication with emphasis on the responsibility for themselves, i.e., for self-care, for arrangement of 
furniture in their rooms, for the schedule of their own time, for voicing their complaints and solutions to resolve them. The other group, the comparison group, received communication that the staff was to take care of their needs as those listed above.

A post-test administered three weeks after the communication showed a significant increase in the self-report of happiness and activity level in the responsibility-induced group as compared to the comparison group. Measures for perceived control showed no significant difference because $20 \%$ of the subjects indicated that they did not understand the questions of perceived control. The interviewer documented an increase in the rating of alertness in the responsibilityinduced group. The nursing staff, as well, documented a significant increase in general improvement and time spent with patients, staff and others as compared to the comparison group. Langer and Rodin (1976) concluded that inducing a greater sense of personal responsibility produces improvements in mental and physical well being.

Reid and zeigler (1980) conducted four reliability and validity studies on a Desired Control Measure to establish a correlation between perceived control and psychological adjustment of the elderly. In the first study, the subject group, comprised of 13 institutionized and 43 noninstitutionalized elderly persons, were interviewed twice with a different interviewer each time. In one interview, the Desired Control Measure was verbally administered. In the 
second interview, the subjects were verbally administered four published measurements of adjustment and well-being. The four measurements included: 1) Life Satisfaction Index $z$ (Adams, 1969), 2) Tranquility-Agitation Scales (Morris \& Sherwood, 1975), 3) Adjustment Measure (Kurtz \& Wolk, 1975) and 4) Affective States (Bradburn \& Caplowitz, 1965).

The second study was a test-retest study conducted one year after the first study. Of the original 56 subjects, 27 subjects were available to participate in the study. In one interview, the Desired Control Measure was verbally administered. In the second interview, three measurements were administered: Life Satisfaction scale and the Tranquility-Agitation Scale, as in the first study, and a third scale measuring Physical Health. It was mentioned that different scales were used in the second, third and fourth studies to get additional information about the subjects' well-being. It was not specified why some scales were used and other were not.

The third and the fourth studies were carried out in a similar manner to the previous studies. However, it was not stated in the article when the third and fourth studies were performed in relation to the first and second studies. In the third study, 63 institutionalized and non-institutionalized elderly persons were verbally administered the Desired Control Measure and the Crowne-Marlow Social Desirability Scale (Crowne \& Marlow, 1960) in the first interview. In the second interview, four questionnaires were administered-1) the Life 
Satisfaction Index Z (Adams, 1969), 2) Subjective Senescence Questionnaire (Reid, Haas \& Hawkings, 1977), 3) Self-Concept Scale (Reid et al., 1977) and 4) the Vitality Scale (Reid et al., 1977).

In the fourth and final study, 52 of the original 63 subjects from the third study were available for retesting one year later. In the first interview, the subjects were given the Desired Control Measure. The second interview consisted of the verbal administration of the Life Satisfaction Index $z$; the Subject Senescence Questionnaire; the Self-Concept Scale; and the self report of Physical Health.

The results of the four studies supported the hypothesis that personal control is an important variable in the psychological adjustment in elderly persons (Reid \& Zeigler, 1980). Fifteen of the 17 correlations between the Desired Control Measure and the other measures of psychological adjustment were statistically significant, $\underline{r}=.44$. Five of the seven correlations between Desired Control Measure in the first and third studies and psychological adjustment measures one year later were significant with the mean correlation $\underline{r}=.46$ (Reid \& Zeigler, 1980).

Another study reported by Davidson and O'Conner (1990) examined the effects perceived control and acceptance of entering a nursing home as variables in changes of functional health and morale. The participants were 30 incoming residents of a 150 bed immediate care facility in Victoria, British Columbia with the mean age of 79.5 years. Interviews 
were conducted on three occasions: 1) after the first week of admission; 2) approximately one month after admission; and 3) approximately four months after admission. The measures examined in the interview consisted of four questions of perceived control pertaining to the admission process; four questions pertaining to the acceptance of the decision to move into the nursing home; the Functional Health Scale (Rosow \& Breslau, 1966) and an abbreviated version of the Philadelphia Geriatric Center Morale Scale (Lawton et al., 1982).

Davidson and O'Conner (1990) found that perceived control had positive effects on health during the first month but negative effects on health and morale between the second and fourth months. Those who were no longer able to exercise the control of decision making in the nursing home environment experienced difficulties in adjustment. The acceptance of the decision to move into the nursing home had positive effects on both health and morale between the second and the fourth months and no effect on the initial adjustment into the nursing home. Acceptance appeared to be an important coping function, but separate from perceived control (Davidson \& O'Conner, 1990).

Issues regarding autonomy of the elderly. Studies have been conducted to evaluate how much autonomy or perceived control elderly people have in different situations, i.e., post-hospital care, admission to a nursing home, in the event of incapacitation, and in family relations. In 1988, Coulton and others did a study on elderly perceptions of post-hospital 
care decision-making. Three hundred and fourteen patients over the age of 60 were interviewed prior to their discharge from the hospital. A measure of 29 items exploring their perceptions of the process of decision making about posthospital care was verbally administered to the subjects. The items designed for this study by Coulton and others (1982) and Dunkle and others (1982) reflected characteristics of ideal decision making activities, as well as, potential barriers to ideal decision making. Two observer measures were also taken by the interviewer, one was the rating of the patient's overall involvement in decision making; the other rating was the degree to which the patient was aware of more than one option for post-hospital care.

In the exploratory factor analysis, items that scored high included: concerns about post-hospital care, family support in decision making, restriction of post-hospital options, perceptions that they had control in the decision making process and the feelings of being rushed. A high score meant that more of the particular aspect of decision making was present in the post-hospital planning process. Items that rated low were perceptions that the decision was out of their control and the certainty that they had the information about options and how they would do after leaving the hospital. A low score indicated that less of the particular aspect of decision making was present.

The results from the observer's ratings showed a moderate, positive correlation between the observer's ratings 
of patients' involvement in decision making with factors of perceived control and certainty of situation. The observer's rating of involvement negatively correlated with hypervigilance and feelings of being rushed. There was also a negative correlation between the observer's rating of the number of alternatives known by the patients and the factor of restricted choices. Coulton and others (1988) explained that aspects of post-hospital decision making are important in determining the extent to which the patient experiences a sense of control over the discharge process. A perceived sense of control has an impact on a patient's successful adaption and post-hospital well-being.

In 1989, High conducted a study to examine elderly preference for decision making in the event of incapacitation. The subjects were 40 non-institutionalized residents, aged 67 to 91, from Fayette County, Kentucky. A semi-structured interview was conducted in which the subjects were encouraged to discuss their preferences and expectations regarding the possibility that they are not able to make their own decisions on long term care.

High found that 908 of the elderly persons interviewed preferred that one or more family members serve as surrogates to make decisions on health care and consent or refusal for treatment. Thirteen of the 19 interviewed who were married stated that an able spouse was their first preference, with 9 of the 16 preferring an adult child consult with the spouse. Adult children were expected to be more involved in decision 
making than the elderly's siblings and other relatives.

Subjects were also asked to respond if they would prefer surrogate decision makers to make decisions according to what the elderly person would want or according to what the surrogate thought was best. It was reported that responses were equal between the two standards of surrogate decision making. One interesting finding was that only six subjects (188) of the 40 subjects interviewed had written living wills. This suggested that these elderly subjects assumed that their autonomy would be preserved by their surrogate without written instructions.

In 1989, Pratt and others did a study to identify how the elderly were involved in their own decision making when they received assistance from their adult children. It was reported that over $80 \%$ of care provided to elderly persons was given by family members, particularly by their adult daughters, which was the focus of this study. The participants in this study were 64 mother-daughter pairs from two small cities in western Oregon and Montana. The interview focused on the process of decision making in six decision areas of elderly living: routine daily care, routine financial decisions, major financial decisions, routine health care, major health care and housing. The subjects responded on different levels for each decision area: how much the mother was involved in decisions, how much the daughter influenced decisions, how confident the subject was with the mother making that decision and how satisfied the subject was with 
the decision making process in that area.

The results found that mothers were not completely independent in decision making. Daughters in the caregiving role were highly influential in their mothers' decisions, especially in the areas of major health, major financial and housing decisions. Over $80 \%$ of the mothers reported that they were always involved in decision making. This coincided with the daughters' report on the mothers' involvement in the decision making. Over $80 \%$ of the daughters reported that their mothers were always involved in decisions. Less than $6 \%$ of the mothers described that they had little to no involvement in the decision making.

Over $90 \%$ of the mothers and daughters reported being "satisfied or very satisfied" with how decisions were made in all six decision areas. Mothers and daughters did not differ in their perceptions of the level of the mothers' involvement in decisions nor in their perceptions of satisfaction with the decision making process (Pratt et al., 1989). The study also showed that influence over mothers' decisions had increased with the increase in age and the decline of physical health of the mother. In conclusion, "the daughters appear to support authentic autonomy in the mothers because the daughters' influence was based largely on the intimate knowledge of their mothers' preferences" (Pratt et al., 1989, p.796).

O'Bryant and Morgan (1990) conducted a study to examine the role of adult children in caregiving activities to their widowed mothers and to examine the widows' attitudes toward 
independence. Two hundred and fifty-two widowed women, ages 60 to 98, were interviewed. Several different measures were used during the interview: 1) Childhelp- modified version of questions used by Lopata (1979) and Kivett (1985); 2) SelfSufficiency scale- 14 specific tasks of activities of daily living which the subjects rated as to how much help was needed on each item; 3) Autonomy scale- three questions created for the study which measured widows' attitudes about independence; 4) Task Index- also created for this study to identify widows' performance on a variety of tasks in the final year before their husbands' death; and 5) Willingness scale- a measure of widows' perceptions of their childrens' willingness to help if the need arises.

Overall, the results showed that most widows were rated moderate to high on self-sufficiency scales. Four out of 10 widows performed two-thirds or more of activities of daily living themselves. The most help was needed in the areas of household repairs, yardwork, and legal issues. Levels of self-suffiency were based on age and health. With the increase in age and a decline in health there was increased dependency on others for assistance. This study showed that $90 \%$ of the help received by widows was from their adult children.

O'Bryant and Morgan (1990) found that widows' perceptions of adult children's willingness to help were higher if the child lived close and if the mother had more children. It was also reported that widows retained their autonomy by their 
performance in familiar activities of daily living. They did not appear to lose autonomy if the tasks now performed by the children, were once in the husband's domain.

Theoretical Approach to the Elderly and Autonomy

The model of human occupation was developed by Kielhofner (1985) to explain how occupational behavior is "motivated, organized and performed" (p. 12). Occupational behavior is defined as an "activity which individuals engage during most of their waking time; it includes activities that are playful, restful, serious, and productive" (Kielhofner \& Burke, 1985, p. 12). According to the model, the human system is composed of a hierarchy of three subsystems: volition, habituation, and performance (Kielhofner, 1985). Kant explained that autonomy is an individual's right to evaluate, make, and implement choices according to their values and goals (Cicirelli, 1989). The three subsystems are the means by which individuals are able to be autonomous.

The volitional subsystem addresses how occupational behavior is motivated. It's components include individuals' beliefs in autonomy, expectations of themselves and their environment, values, goals, and interests. The volitional subsystem organizes how individuals make autonomous choices based upon their values and goals. This in turn enables individuals to explore and master their environment through the performance subsystem and the habituation subsystem, allowing for individuals to carry out autonomous choices on a 
consistent basis. The desire for personal control and autonomy continues through the life span into late adulthood. As individuals mature, their needs, values and interests change (Rogers and Snow 1985). Elderly individuals need a sense of accomplishment, freedom, autonomy, equality, as well as, exciting and comfortable lives to have life satisfaction. If elderly individuals are not able to fulfill these needs, they may experience a lack of personal control or autonomy and dissatisfaction with life (Rogers and Snow, 1985).

The habituation subsystem is the middle level subsystem which organizes occupation behavior through roles and habits (Kielhofner \& Burke, 1985). Roles, such as grandparent, spouse, and friend, are an important source of self-identity for the elderly. Habits are typical patterns that individuals perform on a daily basis and incorporated behaviors that are expected and valued by the environment and society. Roles and habits are important indicators of how individuals successfully adapt to changes in their lives and their environment to remain autonomous and independent (Kielhofner \& Burke, 1985).

In late adulthood, new habits may have to be formed to adjust to age related changes. Individuals experience major changes in roles, i.e., worker to retiree and/or spouse to widow. "Role losses and habit changes may be viewed by elderly individuals' as originating from external sources and biased against their continued independence and personal preferences" (Snow and Rogers, 1985, p. 354). 
The performance subsystem is the lower subsystem that is responsible for the performance of occupational behavior (Kielhofner \& Burke, 1985). It is directly linked to output of the human system. It combines neurological, symbolic, and musculoskeletal constituents that enable individuals to manipulate objects; to manage themselves and events in the environment; and to communicate and interact with others (Kielhofner \& Burke, 1985).

In late adulthood, sensory loss, disuse or misuse atrophy and/or chronic diseases affect elderly individuals' ability to perform occupational tasks (Rogers \& Snow, 1985). Sometimes elderly individuals require assistance from family members, friends or government agencies to perform activities they are no longer capable of performing. This in turn may affect the volition and habituation subsystems by changing their role performance from independent to dependent. This change in role performance may result in their feeling a lack of efficacy and a lack of autonomy or personal control of their environment.

Physical injuries, such as, hip fractures or strokes; role losses such as the death of a spouse; or changes in environment, such as admission to a hospital or nursing home, will have an impact on the three subsystems (Rogers \& Snow, 1985). Occupational therapists serve as "holistic assessors" of the functional status of elderly individuals (Rogers \& Snow, 1985, p. 355). Therapists assess physical abilities, mental processing, performance capabilities, as well as 
personal goals and needs of elderly individuals to develop a rehabilitative treatment plan. Through appropriate intervention, occupational therapists can facilitate restoration of self-determination and belief in their perceived autonomy, and improve performance skills to participate in personal and social roles.

\section{Paternalism}

Definition of paternalism. Paternalism is the moral right to act for another individual, or to force the individual to act, when that action is for the good of the individual concerned (Cicirelli, 1989; Gert \& Culver, 1979; Halper, 1980). People act paternalistically when they believe they know what is best for another person. In his 1980 article, Halper, explained that there are two stages of life in which individuals are apt to be subjected to paternalism: extreme youth and old age. The elderly are objects of paternalism when their abilities decline and they become more dependent on others (Halper, 1980).

Six types of paternalism. In the initial stage of his research, Cicirelli (1989) identified six types of paternalism that have been defined by ethicists, Collopy (1986), Gillon (1985) and Young (1986). Cicirelli used these types as the basis for developing his 30 item Paternalism Scale. The scale was designed to identify peoples' beliefs in paternalism.

1) Direct or strong paternalism is when a person in authority intervenes in another person's decision making, without that 
person's request, consent and/or awareness.

2) Indirect paternalism is when a person in authority uses deception or subtle manipulation to intervene.

3) Benevolent paternalism is when a person in authority participates in the decision, explaining its necessity to the individual.

4) Moderate paternalism is when a person in authority intervenes with the other individual to prevent harm.

5) Weak paternalism is when a person in authority intervenes only when there is mental deterioration of the other individual.

6) Paternalism by default is when otherwise capable, dependent person is indifferent to making decisions, so that the person in authority must make necessary decisions (Cicirelli, 1989, p. 2) .

Personal variables and paternalism. A belief in paternalism is the acceptance of the right to act paternalistically for the welfare of another individual (Cicirelli, 1989). There are certain demographic variables and personality traits that are associated with a belief in paternalism (Cicirelli, 1989 and 1990). A study conducted by Cicirelli (1989) to test the reliability and validity of the final forms of the Respect for Autonomy and Paternalism scales, discusses some of these variables. A total of 209 adult caregivers were given the two questionnaires mentioned above, as well as the Ethical Beliefs Situations Test 
(Cicirelli, 1989), Caregiving Practices Inventory (Cicirelli, 1989), Balanced F-Scale to measure authoritarian personalities (Cherry \& Byrne, 1977), Filial Anxiety Scale (Cicirelli, 1988), Dogmatism Scale (Rokeach, 1960), Old People Scale (Kogan, 1961) and a demographic survey.

Results of the study associating demographic variables with paternalism showed a correlation with the age of the caregiver and paternalism. The older the caregiver, the stronger the belief in paternalism. A positive correlation was also found between lower levels of education and paternalism. It was originally hypothesized that men would be more paternalistic than women, but this was only supported by a marginally significant correlation, $\underline{r}=-.13(\underline{p}<.10)$. Results associating personality traits with paternalism showed that people who were more authoritarian, dogmatic or had negative attitudes toward the elderly held a stronger belief in paternalism.

In a later study by Cicirelli in 1990, 46 adult daughters and their elderly mothers were given several questionnaires to identify their personal characteristics and beliefs in paternalism. The following questionnaires were administered in the study: Paternalism Scale (Cicirelli, 1989), Old People Scale (Kogan, 1961), Dogmatism Scale (Rokeach, 1960), Bengton's Southern California Three Generations Study (Gronvold, 1988), a measure of affective relationships, a demographic survey, and six interview questions regarding the 
elderly mother's health status and the extent of caregiving received by the mother (Cicirelli, 1990).

Results of the correlations for the adult daughters showed a relationship between a stronger belief in paternalism, dogmatism, and a negative attitudes toward the elderly. With the demographic variables, a stronger belief in paternalism was related to the mother's age and the daughter's educational level and occupation. Daughters who had older mothers and lower education and occupation levels had a stronger belief in paternalism. In Cicirelli's (1990) study, measures of the mothers' health and level of received caregiving were not significantly related to their daughters' belief in paternalism, contrary to results of a related study by Collopy (1986) .

Appropriateness of paternalism. There are certain situations where paternalism seems to be appropriate (Cicirelli, 1988; Cicirelli, 1990). Paternalism is ethically justified when there is a high degree of incompetence and great risk of harm which could come to the individual if the paternalistic decision is not made (Abramson, 1985). Abramson (1985) stated that paternalism "infringes" on a person's autonomy and therefore the person in authority should be obligated to prove his or her act as morally acceptable. Abramson described four justifications of morally appropriate paternalistic decision making, 1) when a child does not yet have the capacity to make a decision, 2 ) when an individual is considered mentally incompetent and unable to comprehend the 
results of decision making, 3 ) when the consequences of an act are detrimental and irreversible and 4) when temporary interference with liberty ensures future freedom and autonomy.

Negative effects of paternalism. Halper (1980) offered many reasons why paternalism has negative effects on an elderly person. In general, paternalism may deny older people the opportunity to make a challenging life for themselves. An example was used of a family decision about housing for an elderly parent. The family wanted the parent to move from his neighborhood to a safer environment to avoid crime and the inconvenience of housekeeping. The elderly parent wished to stay in his familiar neighborhood with old friends. Halper explained that in the safe environment, the elderly person may not have the opportunity to have reward and accomplishment of living in a challenging environment.

Paternalism may be used out of convenience for the selfinterest of family and government (Halper, 1980). Halper stated some families institutionalize elderly parents because they have been viewed as a burden to the family. Some government agencies employed to "help" the elderly, operate at a substandard level. They may even encourage elderly dependence in order to increase profits. Families and government agencies may make paternalistic decisions without considering the wishes, needs and point of view of the elderly, feeling they (families and government) know what is best. Halper (1980) explained that the only person who knows what is best for his/her own well-being is that person. 
Abramson (1985) explained the consequences of paternalism may have an impact on self-esteem and self-worth. If elderly individuals are not able to participate in decisions affecting their own lives, they may have negative effects on how they perceive themselves with respect to control of their lives. Furthermore, once other individuals interfere with elderly individuals' right to make decisions, it is assumed (by the definition of paternalism) that the decision makers know what is best for those elderly individuals. Unless elderly people prevent paternalistic decision making to reoccur, their ability to make life decisions may be forfeited in the future (Halper, 1980, Abramson, 1985).

Paternalism in family caregiving. As mentioned before, Cicirelli (1990) pointed out personal-social variables, including negative attitudes, dogmatism, and demographic variables, such as the care receiver's age and the caregiver's education and occupation, are strong predictors of a belief in paternalism. Cicirelli (1990) further hypothesized that an additional factor related to paternalistic caregiving in the family context is a strong attachment bond. The attachment theory (Cicirelli, 1990) states that a child's bond to a parent continues throughout life. As the elderly parent is threatened by the aging process and/or illness, the aim of the adult child is to protect and preserve the existence of that parent. Therefore, a strong attachment bond to the parent relates to a strong belief in paternalism. 
A few studies demonstrate paternalism in the family context (Cicirelli, 1981; Steinmetz \& Amsden, 1983). In 1981, Cicirelli interviewed adult children caring for their elderly parents regarding conflicts between the adult child and the parent. Cicirelli (1981) reported that most conflicts involved the adult childrens' attempts to control the parents' behaviors and their activities. Adult children reported that the majority of the time the paternalistic action was in reaction to the parents' behaviors, not by initiation of the caregiver.

Steinmetz and Amsden (1983) studied the stresses of the caregiving experience. Results showed some adult children resort to force when their parents refuse to eat or take their medications. Eight percent of adult caregivers used physical restraints and $4 \%$ threatened the use of physical force. Conflicts between the adult children and the elderly parent were reported to occur when the adult children were trying to enforce behaviors for the good of the parent.

Paternalism in the health care system. Various articles demonstrate that paternalism exists in the health care system (Collopy, 1988; Halper, 1980). Collopy (1988) discussed how professions inadvertently take control over their clients' decisions making. It was stated that professionals use their knowledge and resources to make decisions in the best interest of their clients. Once this policy of paternalistic decision making is allowed, sometimes these actions go unchecked and unscrutinized, especially when the decisions are beneficial. 
Nevertheless, the result is that the client's autonomy has been compromised.

Halper (1980) suggested that due to the nature of helping behaviors involved in assisting the elderly, geriatric services may recruit heavily from individuals with stronger beliefs in paternalism. Geriatric education and training may also foster this attitude. Halper (1980) also described how hospitals and nursing homes were "more or less self-contained enclaves of paternalism" (p. 478). Within these institutions, elders view the staff as patronizing and indifferent. The staff view the elders as physically incompetent, and incapable of thinking or feeling. Staff, existing in the dominant roles, usually succeed in influencing the elders to conform to the ways of the institution, thus dissolving the elders ability to act autonomously.

Abramson (1985) identified two types of paternalism practiced in the field of social work. The first type, direct intervention, is when the client is prevented from doing what he or she wants to do, i.e., running away, or is required to do something that he or she does not want to do, i.e., going to the hospital. The second type of paternalism is informational paternalism. This involves the manipulation of information, such as, providing false or misleading information or withholding information.

Examples of paternalism in the health care system involving occupational therapy were given in an article by Thomasma (1984). Sample situations were written in reference 
to Thomasma's five freedoms associated with autonomy discussed earlier in the literature review. For example, a challenge to freedom from obstacles was exhibited by the physician who decides that a client is not a good candidate for a certain service or procedure, i.e., occupational therapy. Use of chemical or physical restraints also prevents clients from acting autonomously. In both cases, Thomasma explained that the clients lost their freedom to carry out their desires.

Alternatives to paternalism. Many articles propose alternative methods to paternalistic decision making for the family and the health care system. Moody (1988) suggested a method to offset paternalism: negotiated consent. Negotiated consent is the active participation by the elder or the elder's surrogate and other parties involved, to arrive at a common decision for the elderly individual. This democratic method attempts to reduce the likelihood of any one person making a decision without the elderly individual's consent. Moody explained that this method of decision making is most appropriate when the ideal situation is not attainable and the best has to be made of a bad situation.

Similar models to offset paternalism have been proposed by Cicirelli (1990) and Crabtree (1991). Cicirelli (1990) suggested a way to avoid family paternalistic decision making was to incorporate a collective decision making model. This was done by using one of the following types of autonomy: consultive, joint, delegated, and/or surrogate autonomy (Collopy, 1986; Gillon 1985; and Young, 1986). In all these 
particular types of autonomy, the elderly individual is involved in some part of the decision making process, thus preserving their right to exercise autonomy. Crabtree (1991) proposed the partnership model as an alternative method to paternalism. The model is similar to a business partnership, in which the elderly individual and the family member work together to arrive at a decision. Both the elderly person and the family member have equal authority to act on behalf of the partnership. Once the elderly person becomes incompetent, the partnership is dissolved and the family member assumes the responsibility to make decisions on the behalf of the elder.

\section{Respect for Autonomy and Paternalism Scales}

Families in caregiving roles deal with the daily care, financial, and emotional care of the elderly family member. Their regard for the autonomy of the elderly family member is most important. It is also important to know when it is necessary to step in and take over decision making for that elderly to prevent serious harm. It is hypothesized that beliefs of autonomy/paternalism of caregivers are based on many factors, i.e., existing relationships with the elderly family member, ethical beliefs, values, and personal characteristics of the caregivers (Cicirelli, 1989).

Cicirelli (1989) devised two separate scales to measure the beliefs of caregivers in regard to autonomy and paternalism in care of the elderly. The purpose of these instruments was to assist families and counselors to resolve 
conflicts that arise from caregiving/receiving roles. Information can be used from the results of these scales to assist in the education of future caregivers.

Both the Respect for Autonomy Scale and Paternalism Scale (Cicirelli, 1989) include briefly described situations involving caregiving decisions in relation to health, financial and every day living situations. In the Autonomy Scale, items were written to represent the five types of autonomy: Direct, Consultant, Joint, Delegated and Surrogate. Each item also described the elderly parent at a high or low level of competence. In the Paternalism scales, the items represent one of six types of paternalism: Strong, Indirect, Benevolent, Moderate, Weak and Default. Each item also includes situations concerning health, finance and every day living with a competent elderly parent or elderly parent with a low level of competence.

Instrument development. In the developmental stage of these scales, 80 items concerning respect for autonomy and 80 items concerning paternalism were pooled, reviewed, and edited to 40 items per each scale. These scales were then administered to 10 adult caregivers and 10 elderly parents for a total of 20 individuals. The subjects were asked to critique the items for clarity. After the first administration of the scales, 30 items for each scale were selected as the final questions. The two 30 item scales were then administered to 31 caregiving adults and 39 elderly parents. Analysis for internal consistency, reliability of 
total item score correlations, and item discriminations were conducted. The results were satisfactory and modifications were made to complete the final scales. See Appendix A for copies of the scales.

Testing of the two scales included 147 adult caregivers and 81 elderly parents from a midwestern city with a population of 100,000. The questionnaires were administered in individual's homes in conjunction with an interview. The results of a factor analysis showed two distinct factors for autonomy, which Cicirelli identified as Independent Autonomy and Shared Autonomy. The Independent Autonomy factor included the subcategories of Direct and Consultant autonomy. The Shared Autonomy factor included Joint, Delegated and Surrogate autonomy. The paternalism scale showed one factor, which included six types of paternalism: Strong, Indirect, Default, Benevolent, Moderate, and Weak. Intercorrelations were calculated between Shared Autonomy and the Total Paternalism scores showing a moderate correlation.

Reliability. Internal consistency reliability scores were calculated for the five autonomy subtypes and the six paternalism subtypes, as well as, the total scale scores. In the Respect for Autonomy Scale, subscale reliability ranged from $\underline{r}=.50$ to .73 for adult caregivers and $\underline{r}=.43$ to .54 for elderly parents. Reliability for Total Autonomy was $\underline{r}=.78$. Reliability for the two factors of autonomy for adult children were $\underline{r}=.74$ and $\underline{r}=.78$ for the Independent Autonomy and Shared Autonomy scales, respectively and $\underline{r}=.70$ and $\underline{r}=.74$ for the 
elderly parent group. Cicirelli (1989) considered the reliability for the subscales and factor scores were satisfactory for research purposes (Cicirelli, 1989).

Reliability for six types of paternalism ranged from $\underline{r}=.67$ to .79 for adult children and $\underline{r}=.48$ to .76 for elderly parents. Reliability for the Total Paternalism scores were $\underline{r}=.93$ and $\underline{r}=.90$ for adult children and elderly parents, respectively. Results showed satisfactory reliability on the paternalism scale.

Sixty subjects were retested on both scales after 20 weeks to determine test-retest reliability. The correlations for the adult children were $\underline{r}=.63$ for Independent Autonomy, $\underline{r}=.52$ for Shared Autonomy factor, $\underline{r}=.57$ for the Total Autonomy scale score and $\underline{r}=.88$ for the Total Paternalism scale score. The correlations for the elderly parent retest group were $\underline{r}=.60$ for the Independent Autonomy factor, $\underline{r}=.39$ for the Shared Autonomy factor, $\underline{r}=.53$ for Total Autonomy, and $\underline{r}=.49$ for Total Paternalism. Cicirelli pointed out the scores for Shared Autonomy were low over a 20 week period. The low score of the elderly parent group on paternal beliefs indicated less stability than that of the paternal beliefs of the adult children group.

Validity. Cicirelli (1989) described that the Respect for Autonomy and Paternalism scales are "straight forward in nature", therefore it was said to have face validity (Cicirelli, 1989, p. 7). The instruments were assumed to have 
content validity since the items represented in these scales defined types of autonomy and paternalism.

Cicirelli compared two scales, Ethical Beliefs Situations (Cicirelli, 1989) which he developed for the study and Caregiving Practices Inventory (Cicirelli, 1989) to each of the three factors: Independent Autonomy, Shared Autonomy and Paternalism, to establish criterion validity. On the Ethical Belief Situations test, the Situational Autonomy scores, or who should make the decision, the elderly person or the adult child, were similar to the score of Independent Autonomy from the Autonomy scale. The correlations were $\underline{r}=.40 \quad(\underline{p}<.01)$ for the adult children group and $\underline{r}=.20 \quad(\underline{p}<.10)$ for the elderly parent group. It was assumed that the Situation Autonomy score would be negatively correlated with the paternalism score. The result of the correlations of the Situational Autonomy scores with the Paternalism scores were $\underline{r}=-.57$ $(\underline{p}<.01)$ for the adult children group and $\underline{r}=-.39(\underline{p}<01)$ for the elderly parent group, providing evidence for criterion validity (Cicirelli, 1989).

When comparing the Caregiving Practices Inventory, it was expected the increased number of decisions made by the adult children would be equated to the Paternalism score and the increased number of decisions made by the elderly parent be equated to the Independent Autonomy factor. The results showed low correlations but "in the right direction" (Cicirelli, 1989, p. 7). Correlations ranged from $\underline{r}=.22$ to .32, positively correlating the number of decisions made by 
the adult child and Paternalism and the number of decisions made by the elderly parent and Independent Autonomy. Negative correlations, ranging from $\underline{r}=-.22$ to -.35 , were shown between the number of decisions made by the adult child and Independent Autonomy and the number of decisions made by the elderly parent and Independent Autonomy (Cicirelli, 1989).

In order to test construct validity, the Respect Autonomy and Paternalism scales were compared to other scales measuring various traits or attributes. It was hypothesized that people with authoritarian personalities would have a greater Paternalism score. When compared to the Balance F-scale (Cherry \& Byrne, 1977) measuring authoritarianism, the correlations were $\underline{r}=.24$ with Independent Autonomy and $\underline{r}=-.43$ with Paternalism. Cicirelli (1989) reported both correlations were in the predicted directions. It was also hypothesized that greater belief in paternalism would correlate with a greater concern for the parent's well-being, measured by the Filial Anxiety Scale (Cicirelli, 1988). The correlations were $\underline{r}=.24$ with Paternalism and $\underline{r}=.28$ with Shared Autonomy, relating the adult childrens' anxiety about parental care and belief in paternalism.

Negative attitudes toward the elderly (Kogan, 1961) were correlated $\underline{r}=.54$ with a greater belief in paternalism and positive attitudes toward the elderly were correlated $\underline{r}=.26$ with Independent Autonomy. Dogmatism (Rokeach, 1960) was correlated $\underline{r}=.38$ with Paternalism. A scale was administered to determine if social desirability had an influence on 
beliefs in autonomy and paternalism. The results showed a weak influence. Social Desirability (Crowne \& Marlow, 1960) scores were correlated $\underline{r}=-.01$ with Independent Autonomy, $\underline{r}=-.01$ with Shared Autonomy and .16 with Paternalism.

Many demographic variables were expected to correlate with beliefs in autonomy and paternalism. An adult child's age correlated $\underline{r}=.26$ with Paternalism and $\underline{r}=-.20$ with Independent Autonomy, meaning the older the adult child the more paternalistic their beliefs. A lower educational level was expected to be associated with greater paternalistic beliefs. This was supported with a correlation of $\underline{r}=-.37$. It was hypothesized that men would be more paternalistic than women. This was supported by a weak correlation of $\underline{r}=.17$. 


\section{Chapter III}

\section{Research Procedures/Methodology}

The objective of this study was to describe occupational therapy students' beliefs in respect for autonomy and paternalism regarding care of elderly individuals.

\section{Subjects}

Seventy-two Florida International University (FIU) occupational therapy students, ages 19 to 51 (mean age 28.3), were surveyed. Of the students who participated, 57 were female and 11 were male. The sample was a convenience sample of volunteer junior, senior and professional level masters occupational therapy students enrolled at FIU in the fall semester of 1993 .

Design

This study was a descriptive study in the form of a survey. The subjects were volunteers from the university population, specifically from the College of Health, Occupational Therapy Department.

\section{Procedure}

Permission was requested and granted by the Human Subjects Committee to conduct this survey on campus. To begin the survey, the researcher scheduled two separate times to complete the survey when the students would not be attending classes. Times to administer the survey were coordinated with the occupational therapy faculty to ensure that use of the room would not conflict with other classes or activities. Initially, the researchers went to the students' classes and 
requested their cooperation in completing the survey. The dates and times when the surveys would be scheduled were announced.

On the day the surveys were to be administered, the major professor of this study spoke with the students to remind them of the times of the study and requested their cooperation in completing the survey. At the actual scheduled dates and times, the researcher met the students in the classroom to conduct the survey. The purpose of the survey and the fact that the study is a part of a larger validity study of short versions of the scales was explained. It was also explained it would take approximately one hour to complete the total survey and no one would be penalized if they did not wish to participate. The subjects were asked to sign their names on the survey, only so that they could be readily contacted for a follow-up survey for test-retest reliability. An explanation was given that all responses will be coded by number to assure confidentiality and all results will only be reported in aggregate form.

Once the subjects agreed to participate in the study, the questionnaires were distributed. Consent forms were not required because no risk is involved in filling out this survey. The questionnaires included the Respect for Autonomy Scale (Cicirelli, 1989); the Paternalism scale (Cicirelli, 1989); and a demographic survey (see Appendix A for copies of the questionnaires). The instructions to the students were to read each question carefully and to circle or fill in the 
appropriate response. The questionnaires were handed in to the researcher upon completion. Three subjects were not able to stay long enough to complete the survey due to illness or schedule conflicts. Therefore, these subjects completed the questionnaires on their own and returned them to the Occupational Therapy Department.

\section{Instruments}

The Respect for Autonomy and Paternalism scales used in this study were developed by Victor G. Cicirelli (1989), Professor of Developmental and Aging Psychology at Purdue University in West Lafayette, Indiana. The scales, developed and tested in a midwestern area of the United States, are comprised of 30 items each to identify people's beliefs regarding autonomy and paternalism in caregiving of the elderly.

The Respect for Autonomy scale contains items related to two factors of autonomy: Independent and Shared Autonomy. Independent Autonomy includes two subtypes of autonomy: Direct Autonomy (items numbered $1,6,11,16,21$ and 26); and Consultant Autonomy (items numbered 4,9,14,19,24 and 29). Shared Autonomy includes three subtypes of autonomy: Joint Autonomy (items numbered $2,7,12,17,22$ and 27); Delegated Autonomy (items numbered 5,10,15,20,25 and 30); and Surrogate Autonomy (items numbered $3,8,13,18,23$ and 28 ).

Factor analysis of the Paternalism scale revealed only one factor (Cicirelli, 1989). The Paternalism scale contains items reflecting six subtypes of paternalism: Strong 
Paternalism (items numbered 1,9,14,19 and 26); Indirect Paternalism (items numbered 4,12,17,21 and 23); Benevolent Paternalism (items numbered 2,7,15,25 and 30); Moderate Paternalism (items numbered 5,10,18,22 and 29); Weak Paternalism (items numbered 3,8,13,20 and 24); Default Paternalism (items numbered $6,11,16,27$ and 28).

In both the Respect for Autonomy and the Paternalism scales, one of three general types of caregiving situations: health, finance, or every day living are represented in each item. Elderly care receivers depicting either a low or high competence level are also described. Therefore, a given item might describe a situation where there is a health decision, weak paternalism, and an elderly parent with a high level of competence. This will be referred to in later chapters as an item combination.

Internal consistency and test-retest reliability on each subscale and factor were statistically significant for research purposes (Cicirelli, 1989). Studies of face, content, criterion and construct validity were weak, but in the predicted directions (Cicirelli, 1989).

\section{Statistical Analysis}

Descriptive statistics, such as frequencies and percentages, were compiled for all demographic variables. Means and standard deviations were calculated for age. Overall means and means for educational levels of item sums and the means of the five point rating scale were calculated for the autonomy and paternalism instruments including: total 
scale scores; factor and subtype scores; scores for the three caregiving situations; and elderly parent competence scores. Ranges and standard deviations were also calculated for students' overall means and means by educational levels, factor, subtype scores, the three caregiving situations, and competence level of elderly parents.

To test for differences among the educational levels, $t-$ tests were performed on all scales. T-tests were also calculated to determine if there were differences among students who have an elderly parent over the age of 60 and those who do not. All tests were analyzed used a level of significance of $\underline{p}<.05$. Pearson Correlation Coefficients were calculated to determine relationships between autonomy and paternalism items. Correlations were also found for age with all the autonomy and paternalism items. Cronbach's alpha reliabilities were calculated for the total autonomy and paternalism scales; the two autonomy factors; and the autonomy and paternalism subtypes.

Data was initially recorded by the researcher on WordPerfect 5.1 software. All descriptive and statistical tests were performed using SAS computer software. All tables were generated on WordPerfect 5.1 software.

Limitations of the study

One limitation of this study is that it is a convenience sample of undergraduate and graduate university students. Therefore results cannot be generalized beyond the scope of this study. 


\section{Chapter IV}

\section{Results}

\section{Demographic Data}

Seventy-two subjects volunteered to participate in this study. of the 72 subjects, four did not complete the questionnaire. Therefore, 68 subjects were used to compute demographic and statistical tests. Fifty-seven of the subjects were female and 11 were male. Their ages ranged from 19 to 51, with a mean age of 27.85 and a standard deviation of 7.80. The average age of undergraduate students was 27.1 with a standard deviation of 8.25 and the average age of graduate students was 29.42 with a standard deviation of 6.27. This is consistent with the average age of students attending Florida International University which was 26.31 for undergraduate and 31.13 for graduate students.

Fifty-nine percent of the subjects were never married, $26 \%$ were married, $6 \%$ were divorced and $9 \%$ were living with someone in a marriage-type relationship. Sixty-nine percent of the subjects reported they were in school full-time and not working. Twenty-seven percent were full-time students and worked part-time. Four percent were full-time students, working full-time; part-time students, not working; or parttime students, working part-time. Forty-one percent or (28 subjects) had at least one living parent over the age of 60 . of the 28 subjects, 12 reported that their parents lived locally. Of the 28 subjects that reported having at least one 
parent over the age of 60 , seven indicated that they were in a caregiving role with their elderly parents.

Scoring for the Autonomy and Paternalism Scales

In both the Respect for Autonomy scale and the Paternalism scale, each item was rated on a five point scale, ranging from "strongly agree" (five points) to "strongly disagree" (one point). The Autonomy and Paternalism scores are based on the sum of the items and include total scores and subtotals for the specific types of autonomy and paternalism. Higher scores on the total Autonomy scale and the subscales indicate a greater respect for autonomy. The score range for the Autonomy scale is 30-150 points. Higher scores on the total Paternalism scale and the paternalism subscales indicate a greater belief in paternalism. The score range for the Paternalism scale is also $30-150$ points.

It was originally identified by factor analysis (Cicirelli, 1989) that Independent Autonomy includes the 12 items of the Direct and Consultant Autonomy subtypes. The score range is 12 to 60 points. Shared Autonomy, the second factor, includes the 18 items of Joint, Delegated, and Surrogate Autonomy subtypes. The score range is 18 to 90 points. The score range for each of the five autonomy subtypes is 6 to 30 points. Factor analysis revealed one factor for the paternalism scale (Cicirelli, 1989). The score range for each of the six paternalism subtypes is 5 to 25 points. 
Internal Consistency Reliability for the Scales

Internal consistency reliabilities (Cronbach's alpha) for this sample were calculated for each subscale of the Autonomy and Paternalism scales. Results of the current study were compared with the adult children sample in Cicirelli' study (1989). See Table 1 for results. A desired range for reliability coefficients is above . 80 , which indicates a good correlation between variables (Anastasi, 1988).

The Total Autonomy score for university students in this study ( $r=.79$ ) and the adult children sample in Cicirelli's study $(r=.78)$ were both just below the desired range for reliability coefficients (Anastasi, 1988). Reliabilities for university students and adult children for the Independent Autonomy factor ( $\underline{r}=.64$ and $\underline{r}=.74$, respectively) were not in the desired range for reliability coefficients. The shared Autonomy coefficient for university students was in the desired range $(\underline{r}=.85)$. The original adult children sample was not in the desired range $(\underline{r}=.78)$. Subscale reliabilities for the Automony scale ranged from $\underline{r}=.39$ to .74 , and subscale reliabilities in Cicirelli's study (1989) ranged from $\underline{r}=.50$ to .73, with all reliability coefficients for both samples falling below the desired range.

The reliabilities for Total Paternalism score for the university student sample $(\underline{r}=.94)$ and the adult children sample ( $\underline{r}=.93)$, are both considered good correlations (Anastasi, 1988). Subscale reliabilities for the Paternalism scale for university students ranged from $\underline{r}=.72$ to .94 , 
Table 1

Internal Consistency Reliability for

Autonomy and Paternalism Scales

\begin{tabular}{|c|c|c|c|}
\hline Variable & $\begin{array}{l}\# \text { of } \\
\text { Items } \\
\end{array}$ & $\begin{array}{l}\text { University } \\
\text { Students }\end{array}$ & $\begin{array}{c}\text { Adult } \\
\text { Children }\end{array}$ \\
\hline Total Autonomy & 30 & .79 & .78 \\
\hline Independent Autonomy & 12 & .64 & .74 \\
\hline Shared Autonomy & 18 & $.85 *$ & .78 \\
\hline Direct Autonomy & 6 & .39 & .73 \\
\hline Consultant Autonomy & 6 & .58 & .59 \\
\hline Joint Autonomy & 6 & .56 & .58 \\
\hline Delegated Autonomy & 6 & .74 & .66 \\
\hline Surrogate Autonomy & 6 & .63 & .50 \\
\hline Total Paternalism & 30 & $.94 *$ & $.93 *$ \\
\hline Strong Paternalism & 5 & .79 & .76 \\
\hline Indirect Paternalism & 5 & .79 & .67 \\
\hline Benevolent Paternalism & 5 & $.80 *$ & $.82 *$ \\
\hline Moderate Paternalism & 5 & .78 & .77 \\
\hline Weak Paternalism & 5 & .72 & .72 \\
\hline Default Paternalism & 5 & $.81 *$ & $.84 *$ \\
\hline
\end{tabular}

* signifies coefficient in desired range (Anastasi, 1988)

with Benevolent $(\underline{r}=.80)$ and Default Paternalism ( $\underline{r}=.81$ ) in the desired range for reliability coefficients (Anastasi, 1988), Indirect Paternalism $(\underline{r}=.79)$ and Moderate Paternalism $(\underline{r}=.78)$ falling just slightly below and Weak Paternalism ( $\underline{r}=72$ ) not considered to be within the desired range. Subscale reliabilities for the Paternalism scale in Cicirelli's study ranged from $\underline{r}=.67$ to .79 , falling below the desired range for reliability coefficients. 
Descriptive Data

Autonomy and Paternalism scale scores for undergraduates and graduates. Means of the sums $(\underline{\bar{x}})$ of the Total Autonomy and Paternalism scales, the two factors of autonomy, each autonomy and paternalism subtype, and caregiving situations were calculated for each educational level: undergraduate and graduate students. In addition, scale means ( $\underline{m})$ based on the one to five point rating scale were also calculated for all the previously mentioned combinations. These results are presented in Tables 2 and 3. On the Respect for Autonomy scale, both undergraduate and graduate students were in agreement with autonomous statements. On the Paternalism scale, graduate students were less in agreement with paternalistic statements than undergraduate students. The undergraduate students were neutral, neither agreeing or disagreeing with paternalistic statements. 
Table 2

Autonomy Scores, Factors and Subtypes

by Educational Level

\section{Undergrad Graduate}

Variables Mean SD Mean SD $t$

Total Autonomy

3.71 .34

$3.72 \quad .24$

$-0.30$

p-value

Independent

$3.39 \quad .41$

3.58

.35

$-1.82$

.76

Shared

$3.93 \quad .43$

3.85

.41

0.72

.07

Direct

$3.13 \quad .34$

3.74

.24

$-1.42$

.47

Consultant

$3.85 \quad .50$

3.95

.38

$-0.83$

.16

Joint

$3.89 \quad .47$

$3.77 \quad .44$

0.98

.41

Delegated

$3.98 \quad .52$

3.98

.43

0.00

.33

Surrogate

$3.91 \quad .45$

$3.79 \quad .56$

0.94

1.00

Caregiving situations

Health

Financial

Daily living

$3.69 \quad .27$

$-0.22$

.83

Elderly Parent Competence

Competent

Low competent
$3.77 \quad .40$

$3.63 \quad .37$

$3.75 \quad .29$

0.21

.86

$3.72 \quad .24$

0.99

.32

* $p<.05$ 
Table 3

Paternalism scores and subtypes

by Educational Level

\begin{tabular}{|c|c|c|c|c|c|c|}
\hline \multirow[b]{2}{*}{ Variable } & \multicolumn{2}{|c|}{ Undergrad } & \multicolumn{2}{|c|}{ Graduate } & \multirow[b]{2}{*}{$t$} & \multirow[b]{2}{*}{ p-value } \\
\hline & Mean & SD & Mean & SD & & \\
\hline Total Paternalism & 2.81 & .57 & 2.48 & .54 & 2.27 & $.03 *$ \\
\hline Strong & 2.54 & .66 & 2.09 & .54 & 2.70 & $.01 *$ \\
\hline Indirect & 2.55 & .66 & 2.13 & .56 & 2.48 & $.02 *$ \\
\hline Benevolent & 2.86 & .74 & 2.43 & .85 & 2.09 & $.04 *$ \\
\hline Moderate & 2.97 & .69 & 2.74 & .62 & 1.30 & .20 \\
\hline Weak & 2.77 & .64 & 2.66 & .59 & 0.65 & .52 \\
\hline Default & 3.20 & .75 & 2.81 & .67 & 2.02 & $.05 *$ \\
\hline \multicolumn{7}{|c|}{ Caregiving situations } \\
\hline Health & 2.88 & .56 & 2.44 & .64 & 2.88 & $.01 *$ \\
\hline Financial & 2.81 & .64 & 2.54 & .52 & 1.65 & .10 \\
\hline Daily living & 2.75 & .62 & 2.46 & .57 & 1.83 & .07 \\
\hline \multicolumn{7}{|c|}{ Elderly Parent Competence } \\
\hline Competent & 1.44 & .41 & 1.24 & .41 & 1.80 & .08 \\
\hline Low competence & 2.98 & .72 & 2.94 & .67 & .25 & .80 \\
\hline
\end{tabular}

Overall students' scores on the Autonomy and Paternalism scales. Undergraduate and graduate scores were combined to obtain overall students' scores. The results are summarized in Tables 4 and 5. It was found that, overall, the students were more in agreement than disagreement with autonomous statements $(\underline{m}=3.71)$. For the Autonomy subscales, the students were less in agreement in Direct Autonomy ( $\underline{m}=3.19$ ) and more in agreement in Delegated Autonomy $(\underline{m}=.97)$. In comparison, the total scores for the students were higher on the Respect for Autonomy scale than the Paternalism scale, $\underline{\bar{x}}=111.3$ and 
$\underline{\bar{x}}=81.30$, respectively. The students neither agreed nor disagreed with paternalistic statements; they remained neutral $(\underline{m}=2.71)$.

\section{Table 4}

\section{Overall students' Scores on the}

Respect for Autonomy Scale

\begin{tabular}{lrrrrr} 
Variable & $\overline{\mathbf{x}}$ & SD & $\mathbf{m}$ & \multicolumn{1}{c}{ Score Range } \\
Total Autonomy & 111.30 & .31 & 3.71 & $81.00-143.10$ \\
Independent & 41.28 & .40 & 3.44 & $14.16-54.00$ \\
Shared & 70.02 & .41 & 3.89 & $16.02-88.92$ \\
Direct & 19.14 & .50 & 3.19 & $12.00-27.00$ \\
Consultant & 23.16 & .42 & 3.86 & $15.60-30.00$ \\
Joint & 23.10 & .46 & 3.85 & $15.00-30.00$ \\
Delegated & 23.82 & .48 & 3.97 & $16.02-30.00$ \\
Surrogate & 23.16 & .47 & 3.86 & $16.02-30.00$ \\
Caregiving Situations & 36.70 & .36 & 3.67 & $25.00-47.00$ \\
Health & 37.20 & .35 & 3.72 & $29.00-48.00$ \\
Financial & 38.40 & .35 & 3.84 & $29.00-50.00$ \\
Daily living & 55.80 & .46 & 3.72 & $36.00-72.00$ \\
Elderly Parent Competence & & & $35.04-57.00$ \\
Competent & 43.88 & .38 & 3.66 & & \\
Low Competent & & & &
\end{tabular}

$\underline{N}=68$ 
Table 5

Overall students' Scores on the

Paternalism Scale

\begin{tabular}{lcccr} 
Variable & $\overline{\mathrm{x}}$ & SD & $\mathrm{m}$ & Score Range \\
\hline Total Paternalism & 81.30 & .58 & 2.71 & $39.90-114.00$ \\
Strong & 11.95 & .65 & 2.39 & $5.00-20.00$ \\
Indirect & 12.15 & .66 & 2.43 & $5.00-19.00$ \\
Benevolent & 13.60 & .79 & 2.72 & $6.00-25.00$ \\
Moderate & 14.50 & .68 & 2.90 & $6.00-20.00$ \\
Weak & 13.70 & .63 & 2.74 & $5.00-20.00$ \\
Default & 15.40 & .74 & 3.08 & $6.00-22.00$
\end{tabular}

Caregiving Situations

$\begin{array}{lllll}\text { Health } & 27.40 & .61 & 2.74 & 14.00-38.00 \\ \text { Financial } & 27.20 & .62 & 2.72 & 14.00-41.00 \\ \text { Daily living } & 26.60 & .62 & 2.66 & 10.00-38.00\end{array}$

Elderly Parent Competence

$\begin{array}{llllr}\text { Competent } & 35.70 & .46 & 1.37 & 26.00-63.70 \\ \text { Low Competent } & 11.80 & .79 & 2.97 & 4.00-17.00\end{array}$

$\underline{N}=68$

Given a neutral rating for the Paternalism subscales, the students tended to rate more toward agreement in Default Paternalism $(\underline{m}=3.08)$ and tended to rate more toward disagreement in Strong Paternalism ( $\underline{m}=2.39)$.

A trend was found when comparing autonomy and paternalism scores of items concerning elderly caregiving situations and levels of elderly competence. The students tended to rate more toward agreement in paternalism in a health situation $(\underline{m}=2.74)$ and rate more toward disagreement in paternalism in every day living situations $(\underline{m}=2.66)$. On the autonomy scale, 
the opposite was found, the students were less in agreement in autonomy in health situations $(\underline{m}=3.67)$ and more in agreement in autonomy in every day living situations ( $m=3.84)$. Students disagreed with paternalism in situations when an elderly parent was competent $(\underline{m}=1.37)$ and tended to rate more toward agreement in situations when an elderly parent had a low level of competence $(\underline{m}=2.97)$. When comparing to the autonomy scale, again the opposite was found, students rate higher in autonomy with a competent elderly parent $(\underline{m}=3.72$ ) than autonomy with an elderly parent with a low level of competence $(\underline{m}=3.66)$.

Differences between the university students sample and Cicirelli's adult children sample. In 1989, Cicirelli surveyed 147 adult children who had elderly parents over the age of 60 . Ages of subjects who participated in Cicirelli's study ranged from 27 to 78 with the mean age of 52.16 and the standard deviation of 11.52. Thirty-eight of the subjects were male and 109 were female. Means and standard deviations were reported for the sums of the two autonomy factors and the paternalism scores. The means and standard deviations of this current study are compared to the scores of Cicirelli's study, and presented in Table 6 . In comparing the two studies, the students' overall scores were higher on the two autonomy factors and lower on the Paternalism scale than the sample of adult children. In Independent Autonomy, the overall students mean score was 4.41 points higher than the adult children, demonstrating that students held stronger beliefs in 
Independent Autonomy than the adult children. The overall students' score in Shared Autonomy was similar to the adult childrens' score, a mean difference of .73 points, indicating similar beliefs in Shared Autonomy. The students scored an average of 13.42 points lower on the Paternalism scale than the adult children, demonstrating that students disagreed more in paternalism than the adult children in Cicirelli's study (1989). Differences may be attributed to the difference in ages and/or educational levels between the two samples or the fact that the adult children sample are already in caregiving roles. There was no apparent trend when comparing undergraduate and graduate students to adult children.

\section{Table 6}

\section{Comparison of Means and Standard Deviations}

of Two Studies

Independent Shared

Autonomy Autonomy

Paternalism

\begin{tabular}{|c|c|c|c|c|c|c|c|}
\hline Group & $\mathbf{N}$ & Mean & SD & Mean & SD & Mean & SD \\
\hline $\begin{array}{l}\text { Adult } \\
\text { Children }\end{array}$ & 147 & 36.66 & 5.95 & 69.33 & 6.51 & 95.07 & 17.02 \\
\hline $\begin{array}{l}\text { Overall } \\
\text { Students }\end{array}$ & 68 & 41.07 & 4.96 & 70.06 & 7.32 & 81.65 & 17.52 \\
\hline $\begin{array}{l}\text { Undergrad } \\
\text { Students }\end{array}$ & 48 & 40.49 & 5.12 & 70.63 & 7.74 & 84.24 & 16.86 \\
\hline $\begin{array}{l}\text { Graduate } \\
\text { Students }\end{array}$ & 20 & 42.84 & 4.26 & 68.42 & 6.47 & 73.26 & 15.82 \\
\hline
\end{tabular}


Cicirelli (1990) administered the Paternalism scale to 46 adult daughters who had elderly mothers over the age of 60 . The age of the adult daughters ranged from 27 to 66 years, with the mean age of 49.67 years $(\underline{S D}=8.64)$. The mean of the sum for the Paternalism scale for the adult daughters was $\underline{\bar{X}}=88.41$, with the standard deviation of 16.45. Again, comparing to the current study, the occupational therapy students scored 6.76 points lower on the Paternalism scale than the adult daughters, indicating that the students disagreed more with paternalism than the adult daughters.

A comparison was also made between the students in the current study who had elderly parents over the age of 60 and the adult daughters sample in Cicirelli's study (1990). Students with elderly parents scored $\underline{\bar{x}}=78.90$, compared to $\overline{\mathrm{X}}=88.41$, which was the adult daughters' mean score, a difference of 9.51 points. Again, this illustrates that the student sample disagreed more in paternalism than the adult daughters .

\section{Statistical Analysis}

\section{Differences between undergraduate and graduate scores.}

T-tests were computed $(\underline{p}<.05)$ to determine if there were any significant mean differences between undergraduate and graduate students' scores on the Respect for Autonomy and Paternalism scales. The only significant difference between undergraduate and graduate students on the Autonomy scale was for the Direct Autonomy subtype in a health situation, 
$(p<.04)$. The scale means were $\underline{m}=2.90$ for undergraduates and $\underline{m}=3.30$ for graduates, indicating that graduate students were more in agreement than undergraduates with direct autonomy in a health situation.

Significant differences between undergraduate and graduate students were found in the total mean Paternalism score, health situation in paternalism, as well as, eight paternalism item combinations (refer to Table 3). An item combination is referred to as a type of paternalism involving a competent elderly parent or an elderly parent with a low competence level in one of the three types of caregiving situations. The total mean Paternalism score was significantly different between undergraduates and graduates $(\underline{p}<.03)$. The scale mean was $\underline{m}=2.81$ for undergraduates and $\underline{m}=2.48$ for graduates, indicating that graduate students were less in agreement with paternalistic statements than undergraduate students.

Significant differences between undergraduate and graduate students were found in the overall mean score for Strong Paternalism, $(\underline{p}<.01)$, undergraduates' scale mean was $\underline{m}=2.53$ and graduates' scale mean was $\underline{m}=2.09$. The mean scores for Strong Paternalism in a health and financial situations were also significant, $(\underline{p}<.01)$ for both scores. There were significant differences found between education levels in the Indirect Paternalism score, $(\underline{p}<.02)$, as well as, Indirect Paternalism in a health situation $(\underline{p}<.01)$. The undergraduates' scale mean was $\underline{m}=2.55$, and the graduates' 
scale mean was $\underline{m}=2.13$. Significant differences were found between educational levels in Benevolent Paternalism $(p<.04)$ and Benevolent Paternalism in health $(\underline{p}<.02)$ and financial situations $(\underline{p}<.03)$. The scale means for Benevolent Paternalism for undergraduate students was $\underline{m}=2.86$ and for graduate students was $\underline{m}=2.43$.

There were significant differences between undergraduate and graduate students in Moderate Paternalism in a health situation, $(\underline{p}<.02)$, scale mean for undergraduates, $\underline{m}=3.00$, and for graduates, $\underline{m}=2.60$. The Paternalism by Default mean score was significantly different between educational levels, $(p<.05)$, as well as, Paternalism by Default in health and every day living situations, $(\underline{p}<.04)$ and $(\underline{p}<.03)$ respectively. The scale mean for undergraduates was $\underline{m}=3.20$ and $\underline{m}=2.80$ for graduates.

When grouping all items on the Paternalism scale that contained a statement concerning the health of the elderly parent, five out of six subtypes resulted in significantly different mean scores between undergraduate and graduate students. The total mean score for health situations on the Paternalism scale was $(\underline{p}<.01)$, with the scale mean for undergraduates, $\underline{m}=2.88$, and the scale mean for graduates, $\underline{m}=2.44$. To summarize, all significant differences between undergraduate and graduate students in the paternalism item combinations indicated that graduate students were less in agreement with paternalistic statements than undergraduate students. 
Correlation of autonomy with paternalism. In addition to the tests for the research questions, further statistical tests were performed to gather more information about the sample that was surveyed. A Pearson Correlation Analysis was performed to identify if there were any relationships between the Respect for Autonomy and Paternalism scales. The results of the correlations are presented in Table 7. No relationship was found between the Total Autonomy mean score and the Total Paternalism mean score. However, relationships were found between each of the separate factors of Independent and Shared Autonomy and Paternalism.

Independent Autonomy and one autonomy subtype, Direct Autonomy, were negatively correlated with the Total Paternalism score, $\underline{r}=-.47$ and $\underline{r}=-.48$, respectively. This indicates that those who scored higher on Independent Autonomy items, scored lower on Paternalism items. Independent and Direct Autonomy are types of autonomy where elderly individuals make decisions on their own, whereas the opposite is true in paternalism (Cicirelli, 1989). In paternalism, other individuals make decisions for elderly individuals without their consent. Therefore the results of this study are congruent with the definitions. 
Table 7

Correlation of Autonomy with Paternalism

\begin{tabular}{|c|c|c|c|c|c|c|c|c|}
\hline \multirow{2}{*}{$\frac{\text { Pater- }}{\text { nalism }}$} & \multicolumn{8}{|c|}{ Autonomy Scale } \\
\hline & TA & IND & SHR & $\mathrm{DIR}$ & $\mathrm{CON}$ & JOI & DEL & SUR \\
\hline $\mathrm{TP}$ & .02 & $-.47 *$ & $.28 *$ & $-.48 *$ & -.20 & $.33 *$ & .22 & .20 \\
\hline STR & -.01 & $-.46 *$ & $.28 *$ & $-.42 *$ & $-.27 *$ & $.29 *$ & $.24 *$ & .23 \\
\hline INR & -.17 & $-.32 *$ & -.01 & $-.27 *$ & $-.25 *$ & .07 & -.02 & -.08 \\
\hline $\mathrm{DEF}$ & -.04 & $-.51 *$ & .28 & $-.51 *$ & -.21 & $.33 *$ & .18 & .22 \\
\hline BEN & .16 & $-.38 *$ & $.45 *$ & $-.42 *$ & -.07 & $.43 *$ & $.36 *$ & $.39 *$ \\
\hline MOD & .01 & $-.39 *$ & $.26 *$ & $-.47 *$ & .07 & $.29 *$ & .22 & .18 \\
\hline WEA & -.07 & $-.32 *$ & .12 & $-.29 *$ & -.17 & .21 & .09 & .02 \\
\hline HEA & .03 & $-.44 *$ & $.32 *$ & $-.47 *$ & -.11 & $.31 *$ & $.25 *$ & $.29 *$ \\
\hline ADL & -.07 & $-.46 *$ & .20 & $-.42 *$ & $-.27 *$ & $.26 *$ & .16 & .12 \\
\hline FIN & -.01 & $-.43 *$ & .26 & $-.45 *$ & -.18 & $.34 *$ & .20 & .15 \\
\hline HIC & .00 & $-.48 *$ & $.31 *$ & $-.40 *$ & $-.27 *$ & $.34 *$ & .21 & .27 * \\
\hline LOC & -.05 & $-.32 *$ & .14 & $-.32 *$ & -.11 & .21 & .11 & .02 \\
\hline \multicolumn{9}{|c|}{ * $\underline{p}<.05$} \\
\hline $\begin{array}{l}\mathrm{TP}=\mathrm{TO} \\
\mathrm{STR}=\mathrm{S} \\
\mathrm{INR}=\mathrm{I} \\
\mathrm{DEF}=\mathrm{D} \\
\mathrm{BEN}=\mathrm{B} \\
\mathrm{MOD}=\mathrm{M} \\
\mathrm{WEA}=\mathrm{W} \\
\mathrm{HEA}=\mathrm{H} \\
\mathrm{ADL}=\mathrm{E} \\
\mathrm{FIN}=\mathrm{F} \\
\mathrm{HIC}=\mathrm{H} \\
\mathrm{LOC}=\mathrm{L}\end{array}$ & $\begin{array}{l}\text { otal Pate } \\
\text { Strong } \\
\text { Indirect } \\
\text { Default } \\
\text { Benevoler } \\
\text { Moderate } \\
\text { Weak Pat } \\
\text { Health S } \\
\text { Every day } \\
\text { Financia } \\
\text { High Elde } \\
\text { Low Elder }\end{array}$ & $\begin{array}{l}\text { ernalism } \\
\text { aternali } \\
\text { Paterna } \\
\text { Paternal } \\
\text { nt Pater } \\
\text { Paterna } \\
\text { ernalism } \\
\text { ituation } \\
\text { y living } \\
\text { l Situat } \\
\text { erly Com }\end{array}$ & $\begin{array}{l}\text { sm } \\
\text { lism } \\
\text { ism } \\
\text { nalism } \\
\text { lism } \\
\text { /Patern } \\
\text { Situat } \\
\text { ion/Pat } \\
\text { petence }\end{array}$ & $\begin{array}{l}\text { nalism } \\
\text { tion/Pat } \\
\text { ternalis } \\
\text { e/Patern } \\
\text { /Paterna }\end{array}$ & $\begin{array}{l}\text { TA }=\text { TO } \\
\text { IND }=\mathrm{I} \\
\text { DIR }=\mathrm{D} \\
\mathrm{CON}=\mathrm{C} \\
\mathrm{SHR}=\mathrm{S} \\
\mathrm{JOI}=\mathrm{J} \\
\mathrm{DEL}=\mathrm{D} \\
\mathrm{SUR}=\mathrm{S} \\
t\end{array}$ & $\begin{array}{l}\text { otal Au } \\
\text { Indepen } \\
\text { Direct } \\
\text { Consult } \\
\text { Shared } \\
\text { Joint A } \\
\text { Delegat } \\
\text { Surroga }\end{array}$ & $\begin{array}{l}\text { tonomy } \\
\text { dent Au } \\
\text { Autonom } \\
\text { ant Aut } \\
\text { Autonom } \\
\text { utonomy } \\
\text { ed Auto } \\
\text { te Auto }\end{array}$ & $\begin{array}{l}\text { atonomy } \\
\text { ny } \\
\text { tonomy } \\
\text { ny } \\
\text { y } \\
\text { onomy } \\
\text { onomy }\end{array}$ \\
\hline
\end{tabular}


Shared Autonomy and its three subtypes: Joint, Delegated, and Surrogate Autonomy, positively correlated with Paternalism items ( $\underline{r}=.28$ for Shared Autonomy with Paternalism), indicating that those who scored higher on shared Autonomy items had similar scores on Paternalism items. Shared Autonomy and Paternalism are similar, in that, other individuals take part in elderly decision making. Again, this demonstrates congruency between current findings and the definitions of autonomy and paternalism.

An interesting result was found in reference to items addressing health situations. The health situation in Direct Autonomy did not contribute to the negative correlation between Direct Autonomy and the paternalism item combinations, indicating that health situations are perceived by the students to be more of a shared decision between caregivers and their elderly parents. The same result was found when examining the results of the Joint Autonomy subscale. The health situation in Joint Autonomy contributed the most to the positive correlation between Joint Autonomy and the paternalism item combinations.

Correlation of age with autonomy and paternalism scores.

A Pearson Correlation Analysis was performed to identify relationships between age and the Respect for Autonomy and Paternalism scales. The results are presented in Table 8 . Most Autonomy items did not significantly correlate with age, and therefore were not mentioned in Table 8. Delegated Autonomy in health and everyday living situations were the 
only item combinations that correlated autonomy and age; it was a negative correlation. This may be explained because Delegated Autonomy positively correlated with paternalism item combinations in the prior Pearson Correlation Analysis. A negative correlation was found between age and the Total Paternalism score, indicating as age increases there was a tendency to disagree less with paternalistic statements.

\section{Table 8}

Correlation of Age with the Autonomy and Paternalism Scales

\section{Autonomy/Paternalism Items}

Delegated Autonomy**

Total Paternalism

Strong Paternalism

Indirect Paternalism

Default Paternalism

Benevolent Paternalism

Moderate Paternalism

Weak Paternalism

Health Situation/Paternalism

Financial Situation/Paternalism

Every day living/Paternalism

High elderly competence/Paternal.

Low elderly competence/Paternal. $r$

$-.24$

$-.31$

$-.32$

$-.25$

$-.20$

$-.37$

$-.25$

$-.09$

$-.35$

$-.22$

$-.28$

$-.29$

$-.08$ p-value

.04 *

$.01 *$

$.01 *$

.04 *

.09

$.00 *$

.04 *

.45

.00 *

.07

.02 *

.02 *

.50

* $p<.05$

** only significant autonomy item 
Difference between students who have elderly parents over the age of 60 and those who do not. T-tests were calculated to determine if there were any differences between the responses of students who had a living elderly parent over the age of 60 and those who did not. The only significant differences that were found for autonomy and paternalism items was for the Indirect Paternalism subscale in the health and financial situations, $(\underline{p}<.01)$, with the scale mean of $\underline{m}=2.20$ for those with an elderly parent, and $\underline{m}=2.62$ for those without an elderly parent. This indicated that the students who had an elderly parent over the age of 60 disagreed more with indirect paternalistic statements than the students who did not have an elderly parent over the age of 60 .

In summary, results showed similarities in students' scores on the Respect for Autonomy scale and differences in the scores on the Paternalism scale between educational levels. Differences were found when comparing the current study to Cicirelli's studies (1989 and 1990), as well as, correlations of variables, such as, age and paternalism. 


\section{Discussion}

\section{Research Questions}

Occupational therapy students' beliefs. For people who provide assistance to the elderly, such as, family members and health care professionals, it is important to believe in elderly autonomy. It is assumed that beliefs in autonomy influence behaviors toward the elderly. It has been empirically shown that supporting elderly autonomy facilitates a sense of well-being and life satisfaction for elderly individuals (Langer \& Rodin, 1976; Reid \& Zeigler, 1980; Schulz, 1976). Inappropriate paternalistic acts, on the part of family members or health care providers, minimize elderly autonomy, giving the elderly a sense of loss of control of their lives. As occupational therapists, it is especially important to believe in autonomy in elderly caregiving situations. The guiding premise of our practice is to maximize elderly independence and autonomy through functional and personally relevant activities. It would be difficult to accomplish those goals if therapists did not believe in or support elderly autonomy.

The first research question of this study asked, what are the beliefs of university students regarding autonomy and paternalism in caregiving of the elderly? It was encouraging to report that university students, in general, believe in elderly autonomy in caregiving situations. Therefore, it is 
assumed that these students would be more apt to support autonomy when working with the elderly.

Interesting trends were found in the results. Students had less of a belief in Independent Autonomy and Direct Autonomy, than the other autonomy subtypes. These two types are considered the most autonomous of the autonomy subtypes. This is important because the results indicate that the students believe less in situations where elderly individuals independently make their own decisions. Other interesting trends were variations in attitudes related to different caregiving situations and elderly parent competence. In general, students believed in autonomy, however, they held less of a belief in elderly autonomy in health situations, as compared to the other caregiving situations. As for elderly parent competence, the students held less of a belief in autonomy when the elderly parent had a low level of competence, as compared to a competent elderly parent. The implications of these trends will be addressed later.

University students neither agreed nor disagreed in paternalism. In general they remained neutral in their beliefs. It is important to point out that overall, students did not disagree with paternalism. The students agreed less in Strong Paternalism, where other persons make the decisions for elderly individuals without their consent. They agreed more in Default Paternalism, where other individuals make decisions for the elderly in the event of incapacitation. Default Paternalism is one of those situations where Abramson 
(1985) stated that paternalism was morally acceptable. This indicates that the students' beliefs in paternalism were in a positive direction in reference to paternalism subtypes.

In regard to caregiving situations and elderly parent competence, the trend continued in the Paternalism scale. Overall, students held neutral beliefs in paternalism. However, they were more in favor of paternalism in a health situation, as compared to other caregiving situations. There are several explanations as to why the results illustrate trends in caregiving situations. One explanation may be that since the students are all in the formation process of a health profession, they may feel more comfortable with intervention or sharing in the decision making with situations involving the health of their elderly parents. Another explanation is that elderly parents' health may be more important to students than financial and every day situations, because the potential situations may be more detrimental. Therefore students may feel it necessary to intervene to prevent illness. Lastly, Halper (1980) stated that the health field recruits paternalistic-type individuals, and geriatric education fosters these paternalistic beliefs. Therefore health professionals, already potentially paternalistic by nature, may feel that they should intervene in health issues. This trend should be researched further.

The university students disagreed the most in paternalism with a competent elderly parent, than any specific paternalism subtypes or situation. It is interesting to note that they 
disagreed less in paternalism with an elderly parent with a low level of competence. This result may be important, because occupational therapists work more often with individuals with a low level of competence, whether it be a temporary or permanent condition. This could have implications as to how therapists would support elderly autonomy with confused individuals and needs further investigation.

Differences in beliefs between students. The second research question asked if there are differences between undergraduate and graduate students in the beliefs in autonomy and paternalism in regard to elderly caregiving? In the Autonomy scale, there were no significant differences between the educational levels. In general, undergraduates and graduates held similar beliefs of autonomy in elderly caregiving situations. Undergraduate students held less of a belief in Direct Autonomy than graduate students, indicating that undergraduate students believed less in elderly parents making their own decisions. However, this result was not statistically significant. Again, the trends continued in caregiving situations and elderly parent competence when testing for differences between educational levels. Both undergraduate and graduate students believed less in autonomy in health situations, as compared to the other caregiving situations, and believed less in autonomy in situations describing elderly parents with a low competency level.

Significant differences were found in four out of six 
paternalism subtypes, including the Total Paternalism score. Generally, graduate students disagreed more with paternalistic statements then undergraduate students. It was interesting to find that there was a significant difference between undergraduate and graduate students with paternalism in a health situation. Graduate students disagreed less than undergraduate students with paternalistic statements in a health situation. Further research is needed to explore this finding. Subtypes that were not statistically significant were Moderate and Weak paternalism. Moderate and Weak Paternalism are considered the least paternalistic of the paternalism subtypes, which may indicate that these types of paternalism are not sensitive enough to show significant differences between the educational levels and may represent a gray area between autonomy and paternalistic beliefs.

There are explanations as to why the differences between beliefs of undergraduate and graduate students in paternalism occurred. The differences in paternalism may be age-related or may be due to educational level and experiences prior to seeking a degree in occupational therapy. In general, the professional level graduate students come to the university with bachelor degrees in other field and possibly more work experiences in other fields. The undergraduate students, in general, tend not to have additional degrees or work experiences, therefore the differences in backgrounds may account for the differences between undergraduate and graduate students' beliefs in paternalism. In addition, other 
explanations for the differences in beliefs of paternalism between educational levels may be due to the differences in the curriculum. The graduate students' curriculum promotes independent learning, and problem solving with a focus on philosophy and theory, whereas, undergraduate students' curriculum is based more on the ability to recall information that the professor has given in class. Therefore, the autonomous learning fostered by the graduate program may facilitate less paternalistic beliefs.

Comparison of the current Study to Cicirelli' study

University students held stronger beliefs in elderly autonomy and less of a belief in paternalism than the adult children sample in Cicirelli's study (1989). Cicirelli's (1989) prediction that with increased age there would be an increase in paternalistic beliefs was supported by his study but not by the current study. Graduate students, slightly older than the undergraduate students, held less of a belief in paternalism than undergraduate students.

Explanations of the differences upon comparing the two studies could be attributed to the differences in the range of ages between the two samples, and/or the differences in educational levels of the two groups. Another important difference is that the adult children in the earlier study were already in caregiving roles. Therefore their beliefs may have been based on more practical situations. The majority of the students were speculating about elderly caregiving situations. 
No relationships were found between the Total Autonomy scores and the Total Paternalism scores. However, results of the Pearson Correlation Analysis negatively correlated Independent Autonomy with Paternalism. This indicated that individuals who held a greater belief in Independent Autonomy, held less of a belief in paternalism. Independent Autonomy is considered to be the most autonomous of the autonomy subtypes and most apt to be opposite of paternalism. On the other hand, Shared Autonomy positively correlated with Paternalism, indicating that the two factors have some similar qualities. The similarities of Shared Autonomy and Paternalism is that in both situations other individuals are involved in the decision making process of the elderly.

The results of the correlations illustrate that the Respect for Autonomy scale is a broad measure of autonomy and the Paternalism scale is a stronger scale, as evidenced by its ability to demonstrate differences among variables. These results support Cicirelli's predictions. Cicirelli (1989) stated that the two scales were not measuring bipolar concepts, however he believed that the Shared Autonomy and Paternalism had some similarities and that Independent Autonomy and Paternalism were different.

Variables that Affect Autonomous and Paternalistic Beliefs Relationships between age with autonomy and paternalism. A Pearson Correlation Analysis was performed to determine if 
there were any relationships between age and the Respect for Autonomy and Paternalism scales. Results of the study showed that age was negatively correlated with paternalism in the Total Paternalism score, as well as, four of the six paternalism subtypes. This indicates that as age increased, there was less of a belief in paternalism. These findings were the opposite of Cicirelli's study which showed a weak relationship that with increased age, family members would be more conservative and paternalistic. Conflicting results of the two studies may be attributed to the fact that his sample of adult children were older and closer to the role of caregiver.

Age was negatively correlated with paternalism in health situations, every day living situations and with competent elderly parents. Again this indicated that as age increased, there was less of a belief in paternalism in the above situations. There were no relationships between age and the Respect for Autonomy Scale.

Relationships between educational level and autonomy and paternalism. T-tests were performed to determine if there were any differences in beliefs in autonomy and paternalism between educational levels. Those with a higher educational level (graduate students) held less of a belief in paternalism than those with a lower education (undergraduate students); no significant differences were found between educational levels and autonomous beliefs. Differences may be based on previous educational experiences of the graduate students. The 
findings give some support to Cicirelli's prediction that education level would negatively correlate with paternalism, indicating that the higher the educational level of subjects, the less belief in paternalism.

Relationships between those who have elderly parents and those who do not with autonomy and paternalism. When interpreting the $\underline{T}$-tests to find differences in the responses between the students who have a living elderly parent over the age of 60 and those who do not, a relationship was not established. This indicates that, on the whole, students held similar beliefs in respect for elderly autonomy and paternalism whether or not they have an elderly parent over the age of 60 or not. One paternalism subtype out of all autonomy and paternalism item combinations did show a significant difference between those who have elderly parents and those who do not; the subtype was Indirect Paternalism. Indirect Paternalism is when a person in authority uses deception or subtle manipulation to intervene (Cicirelli, 1989). The students who reported having an elderly parent were more in disagreement with Indirect Paternalism than the students that did not have an elderly parent. Lack of differences between the two groups may be attributed to the relatively young age of the students and small numbers of students identifying with caregiving roles. 
All three subsystems may be affected by the aging process or the affliction of acute or chronic disease. The decrease in the ability to perform daily tasks causes a loss of roles and habits. This in turn, changes the way that individuals perceive themselves in control of their environment. This may lead to feelings of reduced efficacy and a loss of the ability to remain autonomous individuals. At the same time, elderly individuals may also be experiencing a loss of independence and may have had to accept assistance from family and professional caregivers. The fact that university students believe in autonomy and are neutral in their beliefs in paternalism is encouraging. This gives support to the expectations that these students will support autonomy when working with the elderly.

\section{Implications}

In working with the elderly, occupational therapists use functional and personally relevant activities to improve performance skills, and to encourage formation or continuation of roles and habits. As elderly individuals accomplish treatment goals that are personally relevant, they gain control of their environment and of their lives as autonomous individuals. It is important for the quality of their lives, that the elderly are as autonomous as they wish to be.

It is assumed that therapists and caregivers must have a belief in respect for autonomy of the elderly in order to 
support autonomy of the elderly. A better understanding of the beliefs of occupational therapy students toward autonomy in caregiving of the elderly gives an indication of how they may support autonomy when working with the elderly as health care providers. This in turn will assist educators to plan educational training for students that will foster autonomy when working with the elderly.

From this study it was found that generally, the students supported autonomy and held neutral beliefs toward paternalism in elderly caregiving situations. However, in health situations and with elderly individuals with low competence, where health providers may have more impact, students showed a tendency to give less support to autonomy and more to paternalism. Because of the limitations of this sample, no definitive conclusions can be drawn at this time. The relationships of autonomy to competence and health issues need more investigation.

\section{Recommendations}

A larger sample size would be more representative and may give stronger statistical results. Additional research with other populations is needed to gather more information regarding the beliefs of autonomy in elderly caregiving. Examples of these populations include: occupational therapists currently working in the field, students of other health care fields, other types of health care workers, and adult caregivers and their elderly parents. 


\section{Summary}

It is difficult to maintain autonomy throughout the life span. As people grow older, individuals may experience a lack of control in their lives due to the decreased ability to perform skills and maintain social roles. Health care providers as well as family members assisting the elderly, may inadvertently act paternalistically, and not support elderly individuals' ability to make their own decisions. It is important for elderly individuals to be supported to maintain the highest level of autonomy which they desire. Through the application of the model of human occupation, occupational therapists can maintain the highest level of autonomy when working with the elderly.

In this study, 68 undergraduate and graduate occupational therapy students were administered questionnaires to answer two research questions. What are the beliefs of occupational therapy students regarding autonomy and paternalism in caregiving of the elderly? Are there differences in the beliefs regarding respect for autonomy and paternalism in caregiving of the elderly between undergraduate and graduate students? The purpose of this study was to gain a better understanding of the beliefs of occupational therapy students toward autonomy in caregiving of the elderly.

It was concluded that the occupational therapy students in this study, generally believe in elderly autonomy and were neutral toward paternalism in regard to caregiving of the elderly. Therefore, it is assumed that they may be more apt 
to support autonomy when working with the elderly. There were no significant differences between the beliefs of undergraduate and graduate students regarding autonomy. There were differences in beliefs of paternalism between undergraduate and graduate students. Graduate students held less of a belief in paternalism than undergraduate students. 
Abramson, M. (1985). The autonomy-paternalism dilemma in social work practice. Social Casework: The Journal of Comtemporary Social Work, 66, 387-393.

Adams, D. L. (1969). Analysis of a life satisfaction index. Journal of Gerontology, 24, 470-474.

Anastasi, A. (1988). Psychological Testing. New York City, NY: Macmillon.

Arling, G., \& McAuley, W.J. (1983). The feasibility of public payments for family caregiving. Gerontolgist, 23, 300-306.

Bradburn, N. M., \& Caplowitz, D. (1965). Reports on happiness: A pilot study of behavior related to mental health. Chicago, IL: Aldine.

Brody, E. (1985). Parent care as a normative family stress. Gerontologist, 25, 19-29.

Brody, S., Poulshock, S.W., \& Masciocchi, C. (1978). The family caring unit: A major consideration in the longterm support system. Gerontologist, 18, 556-561.

Bruce, M. A. \& Borg B. (1987). The developmental frame. In M. A. Bruce and B. Borg (Ed.) Frames of Reference in Psychosocial Occupational Therapy (pp.193-250). Thorofare, NJ: Slack Incorporated.

Cherry, F., \& Bryne, D. (1977). Authoritarianism. In T. Blass (Ed.), Personality variables in social behavior. (pp. 109-133). Hillsdale, NJ: Erlbaum.

Cicirelli, V. G. (1981). Helping elderly parents: The role of adult children. Boston: Auburn House

Cicirelli, V. G. (1983). Adult children's attachment and helping behavior to elderly: A path model. Journal of Marriage and the Family, 45, 815-822.

Cicirelli, V. G. (1983). A comparison of helping behavior to elderly parents of adult children with intact and disrupted marriages. Gerontologist, $\underline{23}(6), 619-625$.

Cicirelli, V. G. (1988). A measure of filial anxiety regarding anticipated care of elderly parents. Gerontologist, 28, 478-482. 
Cicirelli, V. G. (1989). Measures of Family Members' Beliefs in Respect for Autonomy and Paternalism in Relation to Care of Elderly Parents: The Respect for Autonomy scale and The Paternalism Scales, 1-13.

Cicirelli, V. G. (1990). Relationship of personal-social variables to belief in paternalism in parent caregiving situations. Psychology and Aging, 5(3), 458-466.

Clark, P. G. (1991). Ethical dimensions of quality of life in aging: autonomy versus collectivism in the United States and Canada. Gerontologist, 31(5), 631-639.

Cohen, E. S. (1988). The elderly mystique: Constraints on the autonomy of the elderly with disabilities. Gerontologist, 28(Suppl.), 24-31.

Collopy, B. J. (1986). The conceptually problematic status of autonomy. New York: Fordham University.

Collopy, B. J. (1988). Autonomy in long term care: Some crucial distinctions. Gerontologist, 28 (Suppl.), $10-17$.

Coulton, C. J., Dunkle, R. E., Goode, R. A., \& Mackintosh, $\mathrm{J} .(1982)$. Discharge planning as a decision-making process. Health and Social Work, I, 253-261.

Coulton, C. J., Dunkle, R. E., Chow, J. C., Haug, M., \& Vielhaber, D. P. (1988). Dimensions of post-hospital care decision- making: A factor analytic study. Gerontologist, $\underline{28}(2), 218-223$.

Crabtree, J. L., \& Caron-Parker, L. M. (1991). Long-term care of the aged: ethical dilemmas and solutions. The American Journal of Occupational Therapy, 45(7), 607-612.

Crowne, D. P., \& Marlow, D. (1960). A new scale of social desirability independent of psychopathology. Journal of Consulting Psychology, 24, 349-354.

Davidson, H. A. \& O'Connner, B. P. (1990). Perceived control and acceptance of the decision to enter a nursing home as predictors of adjustment. International Journal of Aging and Human Development, $\underline{31}(4), 307-318$.

Doty, P. (1986). Family care of the elderly. The Milbank Quarterly, 64 (1), 34-71.

Dunkle, R. E., Coulton, C. J., Goode, R. A., \& Mackintosh, J. (1982). Factors affecting the post-hospital care planning of elderly patients in an acute care setting. Journal of Gerontological Social Work, 4, 95-106. 
Gert, B. \& Culver, C. M. (1979). The justification of paternalism. In W. L. Robison \& M. S. Pritchard (Eds.), Medical Responsibility (pp. 1-14). Clifton, NJ: Humana Press.

Gillon, R. (1985). Autonomy and Consent. In M. Lockwood (Ed.), Moral Dilemmas in Modern Medicine (pp. 111-125). New York: Oxford University Press.

Gronvold, R. L. (1988). Measuring affectual solidarity. In D: J. Mangen, V. L. Bengston, \& P. H. Landry, Jr. (Eds.), Measurement of Intergenerational Relations (pp. 74-97). Newberry Park, CA: Sage.

Halper, T. (1980). The double-edged sword: Paternalism as a policy in the problems of aging. Milbank Memorial Fund Quarterly/Health and Society, 58, 472-499.

Hareven, T. K. (1983). Historical changes in the social construction of the life course. Social structure and Life Stages, vol, 171-180.

High, D. M. (1989). Standards for surrogate decision making: What the elderly want. The Journal of Long-Term Administration, $17(2), 8-13$.

Horowitz, A. \& Dobrof, R. (1982). The role of families in providing long-term care to the frail and chronically ill elderly in the community. New York: Brookdale Center on Aging of Hunter College.

Katz, R. S. (1990). Personality trait correlates of attitudes toward older people. International Journal of Aging and Human Development, 31(2), 147-159.

Keilhofner, G. (1985). A Model of Human Occupation: G. Keilhofner (Ed.) Baltimore, MD: Williams \& Wilkins.

Kielhofner, G. \& Burke, J. P. (1985). Components and determinents of human occupation. In G. Kielhofner (Ed.) A Model of Human Occupation (pp. 12-36). Baltimore, Md: Williams \& Wilkins.

Kite, M. E. \& Johnson, B. T. (1988). Attitudes toward older and younger adults: A meta-analysis. Psychology and Aging, $\underline{3}(3), 233-244$.

Kivett, V. R. (1985). Consanquinity and kin level: Their relative importance to the helping network of older adults. Journal of Gerontology, 40, 228-234. 
Kogan, N. (1961). Attitudes toward old people: The development of a scale and an examination of correlates. Journal of Abnormal and Social Psychology, 62(1), 44-54.

Kurtz, J. \& Wolk, S. (1975). Continued growth and life satisfaction. Gerontologist, 15, 129-132.

Langer, E. J. \& Rodin, J. (1976). The effects of choice and enhanced personal responsibility for the aged: A field experiment in an institutional setting. Journal of Personality and Social Psychology, 34(2) 191-198.

Lawton, P., Moss, M., Fulcomer, M., \& Kleban, M. (1982). A research and service oriented multilevel assessment instrument. Journal of Gerontology, 37, 91-99.

Lopata, H. Z. (1979). Women as widows: Support systems. New York: Elsevier.

Moody, H. R. (1988). From informed consent to negotiated consent. Gerontologist, 28(Suppl.), 64-70.

Morris, J., \& Sherwood, S. (1975). A retesting and modification of the Philadelphia Geriatric Center Morale Scale. Journal of Gerontology, 30, 77-84.

National Center of Health Statistics (1992). Highlights from health data on older Americans, United States (NCHS series 3, no. 27). Washington, DC: U. S. Government Printing office.

O'Bryant, S. L., \& Morgan, L. A. (1990). Recent widow's kin support and orientations to self-sufficiency.

Gerontologist, $30(3), 391-398$.

Pratt, C. C., Jones, L. L., Shin, H. Y., \& Walker, A. J. (1989). Autonomy and decision making between single older women and their caregiving daughters. Gerontologist, $\underline{29}(6), 792-797$.

Reid, D. W., \& Ziegler, M. (1980). Validity and stability of a new Desired Control Measure pertaining to psychological adjustment of the elderly. Journal of Gerontology, $35(3)$, $392-402$.

Reid, D. W. , Haas, G., \& Hawkings, D. (1977). Locus of desired control and positive self-concept of the elderly. Journal of Gerontology, 32, 441-450.

Rogers, J. C. \& Snow, T. L. (1985). Later adulthood. In Kielhofner (Ed.) A Model of Human Occupation (pp. 123133). Baltimore, MD: Williams \& Wilkins. 
Rokeach, M. (1960). The open and closed mind: Investigations into the nature of belief systems and personality

systems. New York: St. Martin's Press.

Rosow, I., \& Breslau, N. (1966). Guttman Health Scale for the aged. Journal of Gerontology, 21, 556-558.

Rothbaum, F. (1983). Aging and age stereotypes. Social Cognition, $\underline{2}(2), 171-184$.

Schulz, R. (1976). Effects of control and predictability on the physical and psychological well-being of the institutionalized aged. Journal of Personality and Social Psychology, $\underline{3} 3(5), 563-573$.

Schwalb, S. J., \& Sedlacek, W. E. (1990). Have college students' attitudes toward older people changed? Journal of College student Development, 31, 127-132.

Shorter Oxford English Dictionary (1993). New York, NY: Oxford University Press, Inc.

Steinmetz, S. K., \& Amsden, D. J. (1983). Dependent elders, family stress and abuse. In T. H. Brubaker (Ed.), Family relationships in later life (pp. 173-192). Beverly Hills, CA: Sage.

Sussman, M. B. (1977). The family of old people. In R. H. Binstock \& E. Shanas (Eds.) Handbook of Aging and the Social Sciences. New York: Van Nostrand Reinhold.

Thomasma, D. C. (1984). Freedom, dependency and the care of the very old. Journal of the American Geriatrics Society, 32, $906-914$.

Treas, J. (1977). Family support systems for the aged: Some demographic and social considerations. Gerontologist, 17, 486-491.

U. S. Census Bureau (1991). 1990 Census of Population and Housing, Series P-20, No. 450 , U.S. Government Printing Office, Washington, D.C.

Ward, R. A. (1978). Limitations of the family as a supportive institution in the lives of the aged. The Family Coordinator, 27, 365-372.

Waskel, S. A., \& Powell, F. C. (1988). Use of words to describe aged or elderly: A factor analysis. Gerontology \& Geriatrics Education, $8(1 / 2), 123-131$.

Young, R. (1986). Personal autonomy: Beyond negative and positive liberty. New York: St. Martin's Press. 
Appendix A 


\section{Demographic Survey}

Thank you for agreeing to complete this questionnaire regarding factors that may influence care of the elderly. As the number of elderly persons in our society increases, it is very important that we look at the issues associated with care of the elderly. Your participation is very important to the study.

You are asked to give your name, only because we will need to contact some people for a follow-up survey at a later date. All responses will remain anonymous and information will only be reported as a group.

\section{It is important that you answer all the questions.}

Throughout the questionnaire "elderly parent" refers to a person who is 60 years or older. To answer each question, either circle the number that corresponds to your chosen response or fill in the blank spaces with the appropriate response.

SAMPLE: Name:

(Last) (First)

\section{Gender: 1. Female 2. Male}

1. Identification No.

2. Code No.

3. Name:

(Last)

(First )

4. Address:

(Number) (Street name)

5.

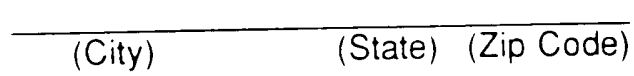

6. Telephone:

7. Are you... 1. Female or 2. Male?

8. In what year were you born? 1

That makes you now years old.

9. Are you now married, widowed divorced, separated. or were you never married?

1. currently married (spouse living)

2. widowed

3. divorced

4. separated

5. never married

6. living with someone in a marriage-like relationship

10. What is your race?

1. American Indian or Alaskan Native

2. Asian or Pacific Islander

3. African American/Black

4. White

5. Other (write in below) 
11. Are you of Hispanic descent?

1. Yes (answer 11A.)

2. No (skip to question 12)

11A. What is your Spanish/Hispanic origin? If more than one, circle the one you consider the most important part of your background.

1. Mexican, Mexican-American, Chicano

2. Cuban, Cubano

3. Puerto Rican, Puertorriqueno, Bouricuan

4. Other (write in below)

12. Do you speak a language other than English at home?
1. Yes
2. No

13. If yes, indicate the language below.
1. Spanish
4. Portuguese
2. French
5. Chinese
3. Creole
6. Other indicate

14. What is your religious affiliation, if any?

1. Catholic

2. Protestant

3. Jewish

4. Muslim

5. None

6. Other (write in)

15. Where do you now live?
1. In a house or condo I own
2. In a rented house or apartment
3. In the home of a family member
4. Other: Specify

16. How far have you gone in school? (circle only one)
1. elementary school
2. some high school
3. high school diploma
4. vocational school beyond high school
5. some college/university study
6. bachelor's degree
7. graduate study 
17. Are you now working full-time, part-time, attending school, keeping house? Circle only one answer. (If you are a student, circle only number 7 .)

1. working full-time (35 hours per week or more)

2. working part-time

3. unemployed, looking for work

4. homemaker (no paid employment outside home)

5. retired - not employed

6. retired - working part-time

7. student

8. Other: Specify

18. Do you have at least one elderly parent living (60 years or older) ?
1. Yes
2. No
If no go to question 28

19. If you do have an elderly parent living, does this person live locally?
1. Yes
2. No

20. Where does your elderly parent live?
1. With me
2. Same city or local area
3. Same state
4. Same country
5. Different country

21. How far away, in terms of travel time, does your elderly parent live?
1. Lives with me
2. In walking distance (few blocks)
3. Thirty minutes or less drive one way
4. More than thirty minutes but less than one hour's drive one way
5. One to three hour drive one way
6. Over three hours drive one way

22. Do you consider yourself to have a caregiving role with your elderly parent?
1. Yes
2. No 23. How do you rate your elderly parent's ability to take care of her/himself from personal care
to managing her/his own business affairs?

1. completely independent; she/he can do everything for self

mainly independent; but she/he needs assistance with one or two tasks

3. does about half of care by self; needs assistance with the other half of the tasks

4. does a few things for self; needs assistance with most tasks

5. mainly dependent; need assistance of another person to do most things 
If your elderly parent lives locally, would you list her/his name and address so we may ask if she/he would also complete a questionnaire?

24. Name (print):

(Last) (First)

25. Address:
(Number)
(Street name)

26.
(City)
(State) (Zip Code)

27. Telephone:

If you are a student, answer the following questions. If you are not a student, please go to the next section. Thank you.

28. In what year of college or university are you currently enrolled? (List your present level, even if you previously have had additional years of school.)
1. year one
2. year two
3. year three (junior)
4. year four (senior)
5. year one professional master's
6. year two professional master's
7. year three professional master's
8. advanced master's

29. What is your status in school?
1. Full-time student; not working
2. Full-time student; working part-time
3. Full-time student; working full-time
4. Part-time student; not working
5. Part-time student; working part-time
6. Part-time student; working full-time

Thank you for completing this section. Please continue on to the next page. 


\section{Respect for Autonomy Scale}

Each of the following statements concerns situations of an elderly parent and an adult child.

Please tell how much you agree or disagree with each statement.

Please read each statement carefully, then indicate the extent to which you agree or disagree by circling the appropriate letters.

First impressions are usually best. GIVE YOUR OPINION ON EVERY STATEMENT but choose only one answer.

There are no right or wrong answers, only those that are true for you.

If you find that the choices do not adequately reflect your own opinion, use the answer that is closest to the way you feel. Thank you.

\begin{tabular}{|c|c|c|c|c|c|c|}
\hline & & 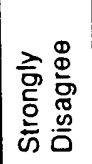 & 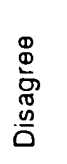 & 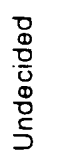 & 这 & 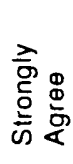 \\
\hline 1. & $\begin{array}{l}\text { If an elderly parent of sound mind decides not to } \\
\text { see the doctor about a chronic condition, the adult } \\
\text { child should support the parent's decision. }\end{array}$ & 1 & 2 & 3 & 4 & 5 \\
\hline 2. & $\begin{array}{l}\text { If an elderly parent who is emotionally unstable } \\
\text { wants to donate money to charity, the adult child } \\
\text { should help the parent decide how much to give. }\end{array}$ & 1 & 2 & 3 & 4 & 5 \\
\hline 3. & $\begin{array}{l}\text { If an elderly parent of sound mind is away and a } \\
\text { broken refrigerator must be replaced, the adult child } \\
\text { should try to decide in the way the parent would. }\end{array}$ & 1 & 2 & 3 & 4 & 5 \\
\hline 4 & $\begin{array}{l}\text { If an elderly parent of sound mind must decide } \\
\text { whether or not to have a series of difficult } \\
\text { physiotherapy treatments, the adult child and the } \\
\text { parent should discuss the treatments but the parent } \\
\text { should decide what is to be done. }\end{array}$ & 1 & 2 & 3 & 4 & 5 \\
\hline & $\begin{array}{l}\text { When an elderly parent who is forgetful asks an } \\
\text { adult child to make decisions about regular living } \\
\text { expenses, the adult child should try to decide things } \\
\text { in the way that the parent would. }\end{array}$ & 1 & 2 & 3 & 4 & 5 \\
\hline & $\begin{array}{l}\text { If an elderly parent who is of sound mind decides to } \\
\text { drive alone across the country, the adult child } \\
\text { should not interfere. }\end{array}$ & 1 & 2 & 3 & 4 & 5 \\
\hline 7. & $\begin{array}{l}\text { When an elderiy parent who knows little about } \\
\text { health matters must decide about having a heart } \\
\text { operation, the adult child and the parent should } \\
\text { decide together. }\end{array}$ & 1 & 2 & 3 & 4 & 5 \\
\hline & $\begin{array}{l}\text { If an elderly parent is too physically ill to make } \\
\text { decisions about paying household bills, the adults } \\
\text { child should make such decisions but try to decide } \\
\text { as the parent would. }\end{array}$ & 1 & 2 & 3 & 4 & 5 \\
\hline
\end{tabular}




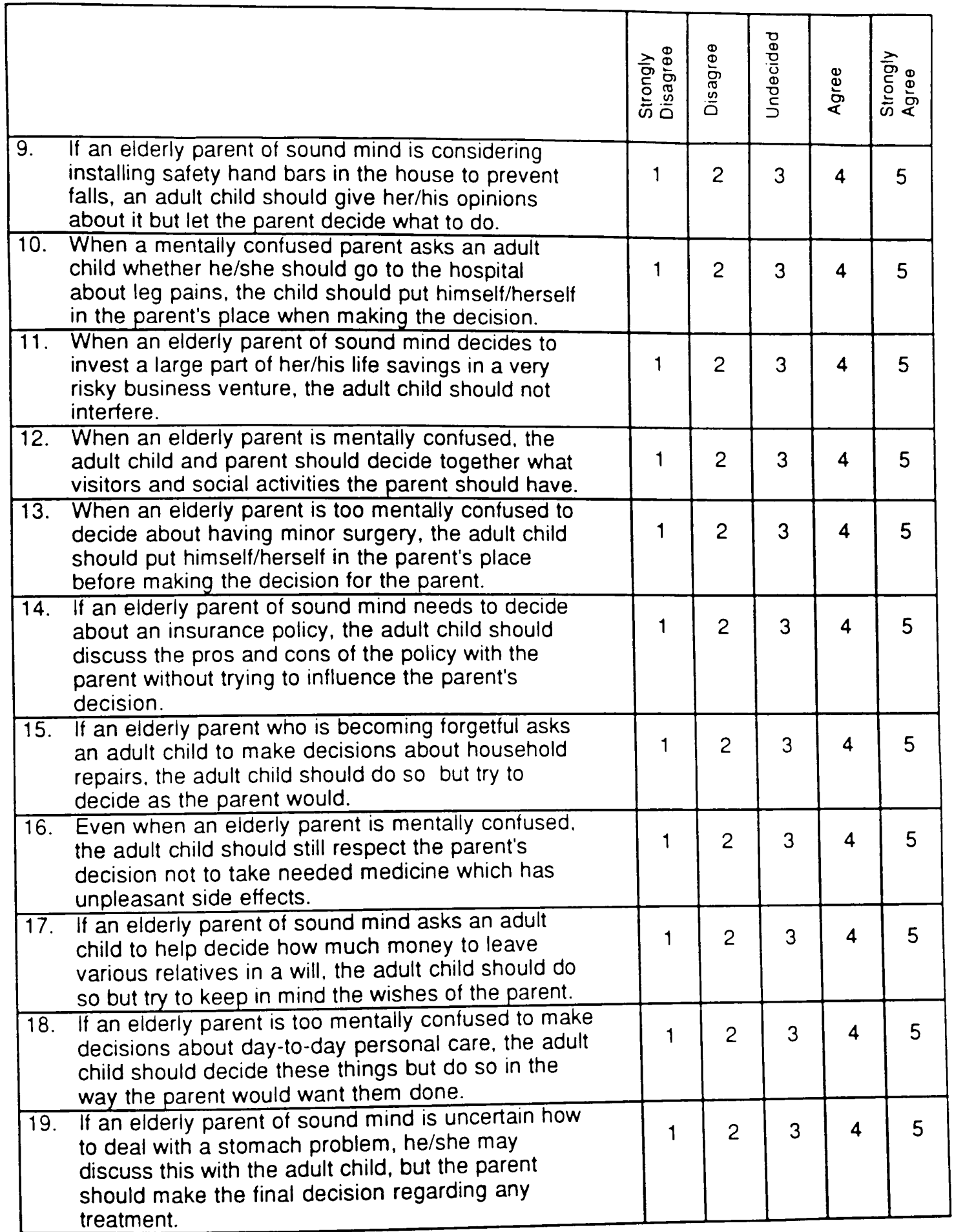


20. If an elderly parent of sound mind asks an adult child to handle banking decisions the adult child should do so but make decisions as the parent would want.

21. When an elderly parent who is very forgetful decides that he/she would be happier living alone in her/his own home no matter what the risk to her/his safety. the adult child should respect that decision.

22. When an elderly parent of sound mind needs to decide whether or not to go on a weight-reducing diet, the adult child and parent together should decide together what to do.

23. If an elderly parent is away on a long trip and cannot be reached for a needed decision about some property, the adult child should make the decision as he/she thinks the parent would have done.

24. If an elderly parent is somewhat mentally confused, the adult child and parent may discuss the parent's needs for new clothing, but the parent should decide what will be bought.

25. If an elderly parent of sound mind asks an adult child whether or not to see a doctor about headaches, the adult child should make a decision that fits in with the parent's views on medical treatment.

26. If an elderly parent who is mentally confused decides to buy more clothes than he/she needs, the adult child should not interfere.

27. If an elderly parent of sound mind needs to decide where to live in later years, the adult child and elderly parent should reach a decision together that best fits the parent's needs and values.

28. If an elderly parent of sound mind ignores the need to make a decision about having medical tests to find the cause of fainting spells, the adult child should try to see things from the parent's point of view to decide whether or not the parent should take the medical tests.

29. If an elderly parent who can no longer think clearly needs to budget money for living expenses, the adult child should discuss the budget with the parent but the parent should make the actual decisions about what to spend.

30. When an elderly parent of sound mind asks an adult child to make decisions about her/his diet, the adult child should do so, but remember the parent's likes and dislikes. 
Each of the following statements concerns an elderly parent and an adult child. Please tell how much you agree or disagree with each statement.

Please read each statement carefully, then indicate the extent to which you agree or disagree by circling the appropriate letters.

First impressions are usually best. GIVE YOUR OPINION ON EVERY STATEMENT but choose only one answer.

There are no right or wrong answers, only those that are true for you.

If you find that the choices do not adequately reflect your own opinion, use the answer that is closest to the way you feel. Thank you.

\begin{tabular}{|c|c|c|c|c|c|}
\hline & 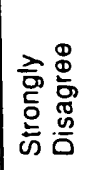 & 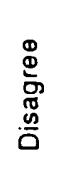 & $\begin{array}{l}\text { D } \\
\stackrel{D}{0} \\
\stackrel{D}{\Phi} \\
\stackrel{D}{J}\end{array}$ & 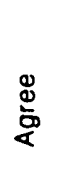 & 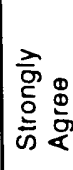 \\
\hline $\begin{array}{l}\text { 1. No matter how much an elderly parent objects, the } \\
\text { adult child should do whatever he/she thinks is best } \\
\text { for the parent's health in the long run. }\end{array}$ & 1 & 2 & 3 & 4 & 5 \\
\hline $\begin{array}{l}\text { 2. When an adult child knows more than an eiderly } \\
\text { parent about how to manage money, the child } \\
\text { should take charge of the parent's spending, but } \\
\text { explain to the parent why it's necessary to do so. }\end{array}$ & 1 & 2 & 3 & 4 & 5 \\
\hline $\begin{array}{l}\text { 3. When an elderly parent can no longer take care of } \\
\text { himself/herself, he/she no longer has any say in } \\
\text { how an adult child takes care of him/her. }\end{array}$ & 1 & 2 & 3 & 4 & 5 \\
\hline $\begin{array}{l}\text { 4. If an adult child decides it is best for an elderly } \\
\text { parent's health, he/she should slip needed } \\
\text { medicine into the parent's food so the parent has no } \\
\text { chance to object. }\end{array}$ & 1 & 2 & 3 & 4 & 5 \\
\hline $\begin{array}{l}\text { 5. If an elderly parent decides to risk a great deal of } \\
\text { money in a business opportunity that is likely to fail. } \\
\text { the adult child should forbid it. }\end{array}$ & 1 & 2 & 3 & 4 & 5 \\
\hline \begin{tabular}{|l}
$6 . \quad$ If an elderly parent pays no attention to getting a \\
proper diet, the adult child should decide what the \\
parent will eat.
\end{tabular} & 1 & 2 & 3 & 4 & 5 \\
\hline $\begin{array}{l}\text { 7. When necessary, an adult child should force an } \\
\text { elderly parent to stick to a treatment the doctor } \\
\text { ordered, but also explain the need to do so to the } \\
\text { parent. }\end{array}$ & 1 & 2 & 3 & 4 & 5 \\
\hline $\begin{array}{l}\text { 8. Regardless of what the parent thinks should be } \\
\text { done, if the parent is too confused to handle money } \\
\text { any more the adult child should decide how to } \\
\text { spend the money for the parent's benefit. }\end{array}$ & 1 & 2 & 3 & 4 & 5 \\
\hline
\end{tabular}




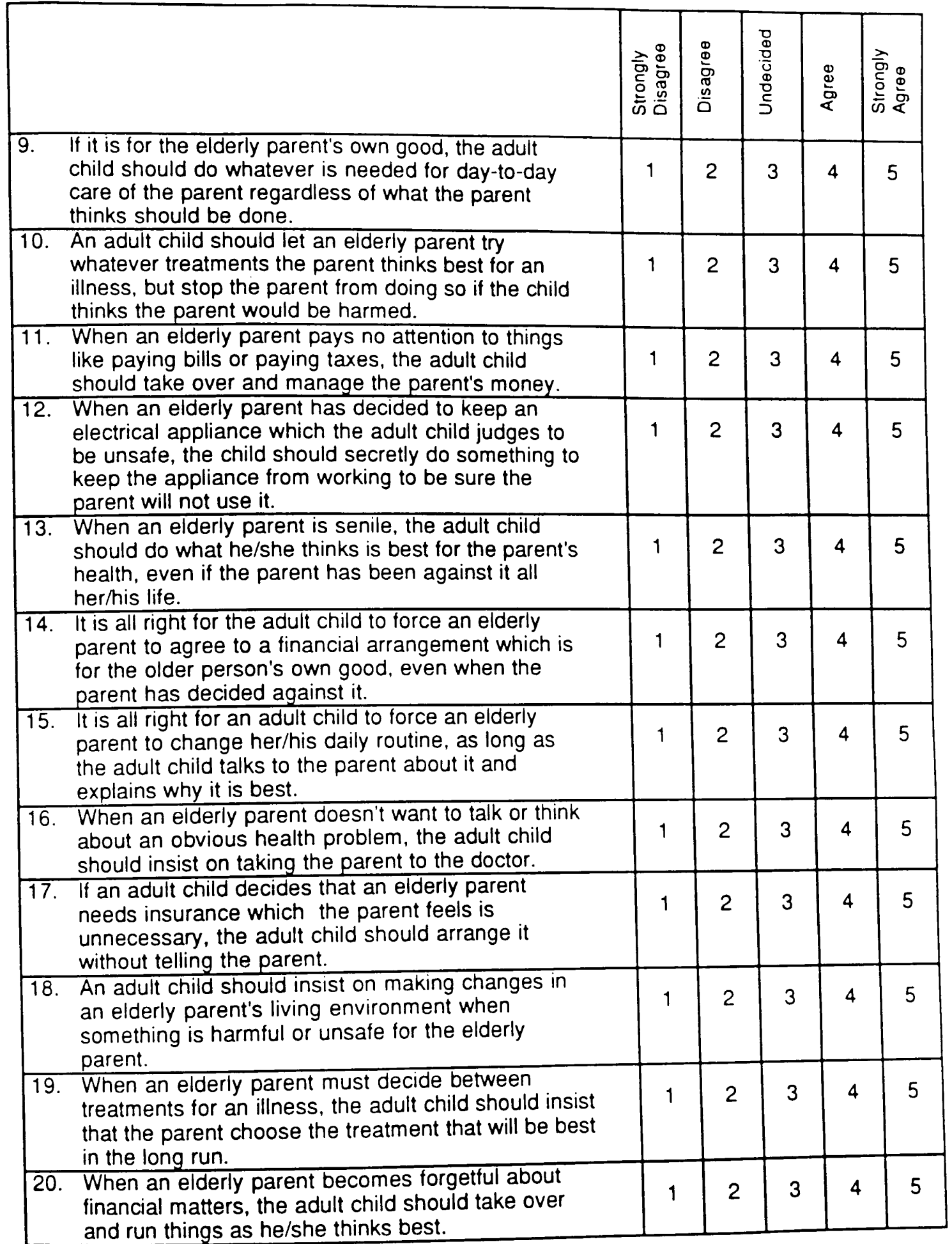




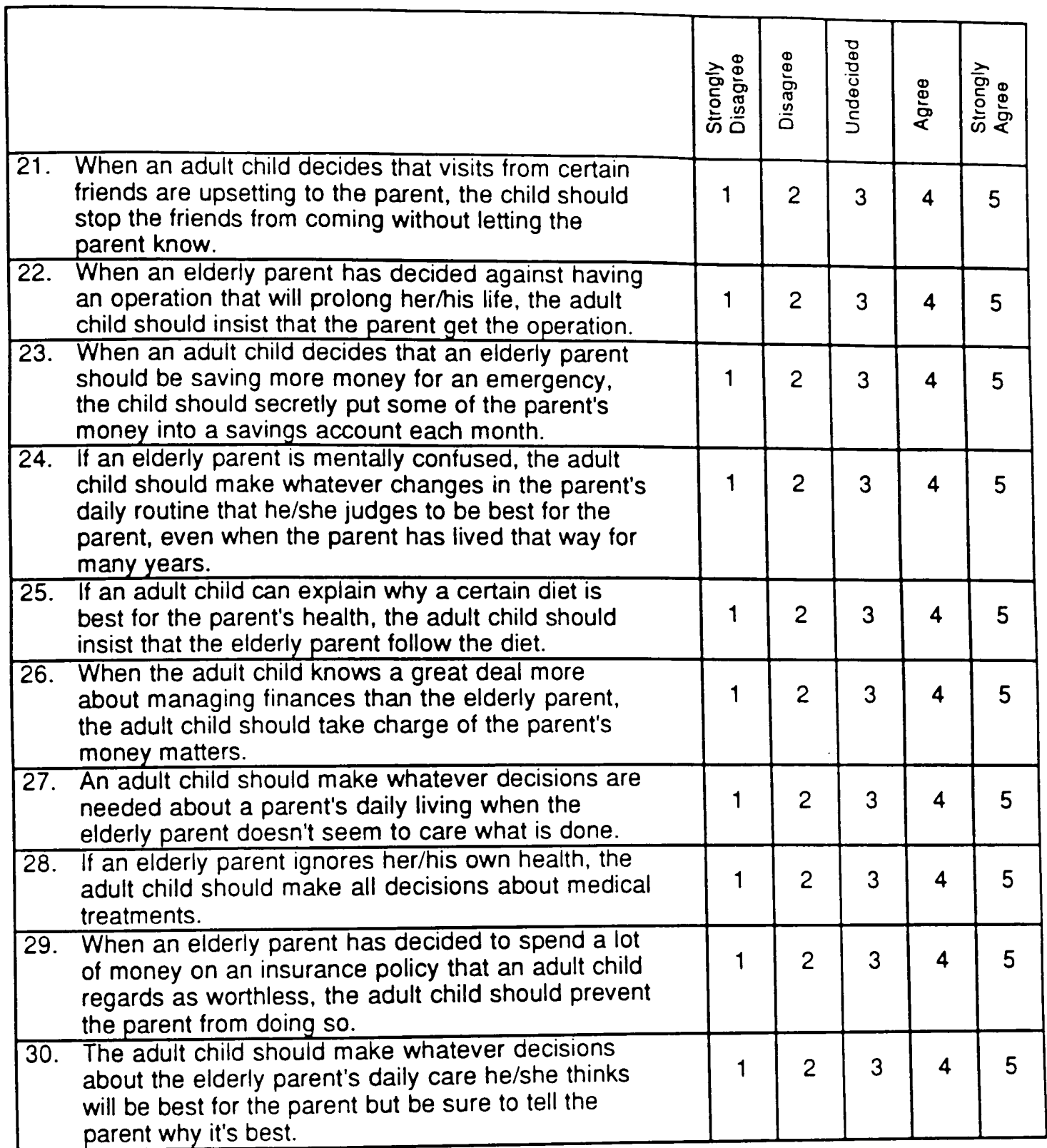

